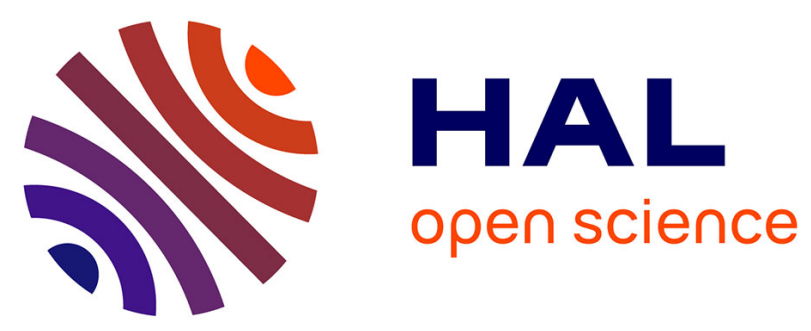

\title{
Assessing the cost-effectiveness of hepatitis C screening strategies in France
}

Sylvie Deuffic-Burban, Alexandre Huneau, Adeline Verleene, Cécile Brouard, Josiane Pillonel, Yann Le Strat, Sabrina Cossais, Françoise Roudot-Thoraval, Valérie Canva, Philippe Mathurin, et al.

\section{To cite this version:}

Sylvie Deuffic-Burban, Alexandre Huneau, Adeline Verleene, Cécile Brouard, Josiane Pillonel, et al.. Assessing the cost-effectiveness of hepatitis C screening strategies in France. Journal of Hepatology, 2018, 69 (4), pp.785-792. 10.1016/j.jhep.2018.05.027 . inserm-02472188

\section{HAL Id: inserm-02472188 https://www.hal.inserm.fr/inserm-02472188}

Submitted on 10 Feb 2020

HAL is a multi-disciplinary open access archive for the deposit and dissemination of scientific research documents, whether they are published or not. The documents may come from teaching and research institutions in France or abroad, or from public or private research centers.
L'archive ouverte pluridisciplinaire HAL, est destinée au dépôt et à la diffusion de documents scientifiques de niveau recherche, publiés ou non, émanant des établissements d'enseignement et de recherche français ou étrangers, des laboratoires publics ou privés. 


\section{Assessing the cost-effectiveness of hepatitis C screening strategies in France}

Sylvie Deuffic-Burban ${ }^{1,2}$, Alexandre Huneau ${ }^{1}$, Adeline Verleene ${ }^{1}$, Cécile Brouard ${ }^{3}$, Josiane

Pillonel $^{3}$, Yann Le Strat ${ }^{3}$, Sabrina Cossais ${ }^{1}$, Françoise Roudot-Thoraval ${ }^{4}$, Valérie Canva ${ }^{5}$,

Philippe Mathurin ${ }^{2,5}$, Daniel Dhumeaux ${ }^{6}$, Yazdan Yazdanpanah ${ }^{1,7}$

${ }^{1}$ IAME, UMR 1137, Inserm, Université Paris Diderot, Sorbonne Paris Cité, Paris, France

${ }^{2}$ Université Lille, Inserm, CHU Lille, U995 - LIRIC - Lille Inflammation Research

International Center, Lille, France

${ }^{3}$ Santé publique France, Saint-Maurice, France

${ }^{4}$ Service Santé Publique, Hôpital Henri Mondor, Créteil, France

${ }^{5}$ Service des Maladies de l'Appareil Digestif et de la Nutrition, Hôpital Huriez, CHRU Lille, Lille, France

${ }^{6}$ Inserm U955, Hôpital Henri-Mondor, Créteil, France

${ }^{7}$ Service de maladies Infectieuses et tropicales, Hôpital Bichat Claude Bernard, Paris, France

Corresponding author: Sylvie Deuffic-Burban, IAME UMR1137, Inserm, Université Paris

Diderot et Paris Nord, UFR de Médecine Site Bichat, 16 rue Henri Huchard, 75018 Paris,

France. Tel: 33 (0)1 57277534 - Fax: 33 (0)1 572775 21, sylvie.burban@inserm.fr

Key words: chronic hepatitis C; cohort Markov model; effectiveness analysis; costeffectiveness analysis; interferon-free direct-acting antiviral agents; screening

Electronic word count: 6,016

Number of figures and tables: 3 figures -5 Tables 
Financial support statement: This work was supported by the French Agence Nationale de Recherche sur le Sida et les Hépatites virales (ANRS, http://www.anrs.fr/).

Conflict of interest: Sylvie Deuffic-Burban reports having received research grants from Janssen and MSD; consultancy honoraria from Abbvie, Bristol-Myers Squibb, Gilead, and MSD; and lecture fees from Bristol-Myers Squibb and Gilead. Françoise Roudot-Thoraval reports having received consultancy honoraria from Gilead; and lectures fees from BristolMyers Squibb, Gilead, MSD, Janssen and AbbVie. Valérie Canva reports having received consultancy honoraria and lecture fees from Abbvie, Bristol-Myers Squibb, Janssen, Gilead and MSD. Philippe Mathurin reports having received consultancy honoraria from Abbvie, Bayer, Bristol-Myers Squibb, Gilead, MSD, Sanofi, and Verlyx; and lecture fees from Bayer, Bristol-Myers Squibb, Gilead, and MSD. Yazdan Yazdanpanah reports having received consultancy honoraria from Abbvie, Bristol-Myers Squibb, Gilead, MSD, Pfizer, Tibotec and ViiV Healthcare.

Authors contributions: SDB and YY have had the conception and design of the work. SDB, $\mathrm{AH}, \mathrm{AV}, \mathrm{CB}, \mathrm{JP}, \mathrm{YLS}$ and SC acquired the data. SDB performed the analysis. All authors contributed to interpretation of data. All authors participated to writing and revision of the paper, and approved the final version to be published. 


\section{Abstract (274 words)}

Background and aims: In Europe, hepatitis C virus (HCV) screening still targets people at high risk of infection. We aim to determine the cost-effectiveness of expanded HCV screening in France.

Methods: A Markov model simulated chronic hepatitis $\mathrm{C}(\mathrm{CHC})$ prevalence, incidence of events, quality adjusted life years (QALYs), costs and incremental cost-effectiveness ratio (ICER) in the French general population, aged 18 to 80 years, undiagnosed for $\mathrm{CHC}$ for different strategies: $\mathrm{S} 1=$ current strategy targeting the at risk population; $\mathrm{S} 2=\mathrm{S} 1$ and all men between 18 and 59 years; S3=S1 and all individuals between 40 and 59 years; S4=S1 and all individuals between 40 and 80 years; S5=all individuals between 18 and 80 years (universal screening). Once $\mathrm{CHC}$ diagnosed, treatment was initiated either to patients with fibrosis stage $\geq$ F2 or regardless of fibrosis. Data were extracted from published literature, a national prevalence survey, and a previously published mathematical model. ICER were interpreted based on one or three times French GDP per capita $(€ 32,800)$.

Results: Universal screening led to the lowest prevalence of CHC and incidence of events, regardless of treatment initiation. When considering treatment initiation to patients with fibrosis $\geq F 2$, targeting all people aged 40-80 was the only cost-effective strategy at both thresholds $(26,100 € /$ QALY). When we considered treatment for all, although universal screening of all individuals $18-80$ is associated with the highest costs, it is more effective than targeting all people 40-80 and cost-effective at both thresholds (31,100€/QALY).

Conclusions: In France, universal screening is the most effective strategy and is cost-effective when treatment is initiated regardless of fibrosis stage. From an individual and especially from a societal perspective of HCV eradication, this strategy should be certainly implemented. 


\section{Lay summary}

- In the context of highly effective and well tolerated therapies that are now recommended for all patients, a reassessment of HCV screening strategies is needed.

- An effectiveness and cost-effectiveness study of different strategies targeting either the at risk population, specific ages or all individuals was performed.

- In France, universal screening is the most effective strategy and is cost-effective when treatment is initiated regardless of fibrosis stage. From an individual and especially from a societal perspective of $\mathrm{HCV}$ eradication, this strategy should be certainly implemented. 


\section{Introduction}

In Europe, recommendations for hepatitis $\mathrm{C}$ virus $(\mathrm{HCV})$ screening still target only people at high risk of infection [1]. With this screening strategy, around $40 \%$ of infections are still not detected in France [2]; around 75,000 individuals in 2014 [3].

The current situation is in favor of a reassessment of the screening strategy for several reasons: (i) hepatitis $\mathrm{C}$ is diagnosed at an advanced stage of the disease in more than one patient out of 10 , corresponding to a delay in diagnosis [4, 5]; (ii) recent availability of highly efficacious and well tolerated treatments (i.e.; direct-acting antiviral (DAA)-based regimens) [6]; (iii) in addition to standard serological tests, rapid screening tests now exist for viral hepatitis $\mathrm{C}$, that can help to expand the availability of screening outside health facilities, and to develop new strategies especially for those who have no access to interventions implemented in healthcare facilities [7]. Since 2012, the United States (US) and Canada have advocated one-time testing in specific birth cohorts, corresponding to those with the highest prevalence of hepatitis $C$ [8-10]. It is however not clear that these strategies are applicable to other countries with different HCV epidemiological profile. In addition, the cost-effectiveness analyses underlying these strategies were conducted with past treatments that were much less effective than present DAA.

Although France is one of the countries with the highest HCV screening level, the impact of treatment may be increased with improvement in $\mathrm{HCV}$ detection and therapeutic management [11]. Early detection can allow earlier introduction of antiviral treatment leading to a reduction in morbidity and mortality [12]. It can also allow a reduction in the cost of care, because an effective and early treatment may prevent progression to the costly complications, such as cirrhosis and/or hepatocellular carcinoma [13]. Finally it can have a societal benefit because testing and treatment of hepatitis in particular in at risk population may avoid $\mathrm{HCV}$ 
transmission and help control HCV epidemic [14]. Currently, in France, a group of experts designed by the ministry of health to elaborate recommendations on HCV care and optimization of screening recommended universal screening for hepatitis $\mathrm{C}$ for the purpose of elimination [15]. However, universal screening - and how to launch it - is not yet decided to be funded by the Ministry of Health and by the Haute Autorité de la Santé.

The objective of this study is to evaluate the effectiveness, cost and cost-effectiveness of different hepatitis $\mathrm{C}$ screening strategies to guide the public authorities in the reassessment of the screening policy. 


\section{Materials and Methods}

\section{Study design}

We designed a decision analysis model to evaluate life expectancy, life expectancy in discounted quality adjusted life years (QALYs), direct lifetime discounted costs and incremental cost-effectiveness ratio (ICER) for five different HCV screening strategies among the French 18-80 general population undiagnosed for chronic hepatitis C (CHC, HCV-RNA positive individuals): $\mathrm{S} 1=$ current strategy: $\mathrm{HCV}$ screening is only offered to high-risk individuals identified through an imperfect assessment of their risk factors; $\mathrm{S} 2=\mathrm{S} 1$ and all men between 18 and 59 years; S3=S1 and all individuals between 40 and 59 years; S4=S1 and all individuals between 40 and 80 years; S5=all individuals between 18 and 80 years. Once $\mathrm{CHC}$ diagnosed, treatment was initiated either to patients with fibrosis stage $\geq \mathrm{F} 2$ or regardless of fibrosis. We also estimated the impact of each strategy, first in terms of CHC prevalence one year later among the undiagnosed general population and, second, in terms of cumulated incidence of cirrhosis (F4), decompensated cirrhosis, HCC and liver-related deaths at 10 and 20 years among the $\mathrm{CHC}$ population.

The ICER between two strategies was defined as the additional cost of a specific strategy compared with the next least expensive strategy, divided by its additional clinical benefit. Strategies were considered inefficient and excluded from ICER calculations if they resulted in higher costs but less of benefit, or had a higher ICER than a more effective strategy [16]. We adopted a modified_societal perspective excluding indirect costs [17]. We used a lifetime horizon of 50 years and discounted all future costs and clinical benefits at $4 \%$ per year over the first 30 years, decreasing from $4 \%$ to $2 \%$ thereafter, based on French guidelines for costeffectiveness analysis [17]. Costs were expressed in 2017 Euro $(€)$. Given that no threshold is defined by French Health Authorities, we used the GDP per capita (€32,800 in 2015 [18]) for 
interpreting the ICER, following the WHO's Commission on Macroeconomics and Health [19]: interventions that have an ICER of less than three times GDP per capita are considered as cost-effective (i.e. willingness to pay (WTP) of $€ 98,400$ ), and those that have an ICER of less than one times GDP per capita as very cost-effective (i.e. a WTP of $€ 32,800$ ). As the threshold of $€ 98,400$ can be considered too high and contestable, we interpreted our results according to both thresholds [20].

\section{Model structure}

A testing decision tree was combined with a previously published Markov-based model to simulate the trajectory of all individuals according to each testing strategy (Supplementary material) [21]. For those screened for $\mathrm{CHC}$ and eligible for treatment, treatment was introduced into the natural course of the disease.

\section{Input parameter for the models}

\section{Study population}

The study population consisted of the French general population aged 18 to 80 years, without any known diagnosis of HCV-RNA positivity. Characteristics of this population were issued from the 2004 national seroprevalence survey of the French National Public Health agency [2, 3]. First, we obtained the estimated proportion of CHC (HCV-RNA positivity) in this study population according to the presence or absence of risk factors (Table 1). Accordingly, the estimated prevalence of CHC among French undiagnosed 18-80 general population was $0.23 \%$. Second, in the risk-based strategy, individuals were assumed to be tested as observed in the 2004 French survey, i.e. between $4 \%$ and $18 \%$ for individuals without risk factors and 
between $10 \%$ and $19 \%$ for those with risk factors (Table 2). For the new screening strategies, we assumed that $50 \%$ of targeted individuals were tested. Third, because excessive alcohol abuse was recognized as a risk factor of $\mathrm{CHC}$ progression [22], we obtained the distribution of excessive alcohol abuse by gender and age using a previously published model [23], i.e. in males: $26 \%$ in $18-39,18 \%$ in $40-59$ and $3 \%$ in $60-80$; in females: $6 \%, 4 \%$ and $2 \%$, respectively. Finally, our previous modeling was also used to stratify the study population into fibrosis stage (Supplementary Table 3) [23]. More details are provided in Supplementary material.

\section{Virological response rate}

The probabilities of SVR considered were: $95 \%$ in stages of fibrosis F0 to F4, 85\% in decompensated cirrhosis [24]. Patients who achieved a sustained virological response (SVR) to treatment at different stages of fibrosis before cirrhosis (F4) no longer had fibrosis progression. In contrast, patients who showed a SVR at stage F4 remained at risk of developing complications and death, but at lower risks as obtained with past IFN-based treatment [25]. Because of lack of data and to remain conservative, patients who achieved a SVR in decompensated cirrhosis were considered to have the same risk of progression as that of untreated patients. In patients who did not achieve SVR, fibrosis progression was considered the same as that of untreated patients.

\section{Costs}

We included direct medical lifetime costs associated with HCV screening, and HCV disease treatment and care, as previously described [26] (Supplementary Material and Supplementary Table 4). Following the French treatment recommendations and recent negotiations of drug prices, we have considered a unique price of $28,730 €$ for a 12 -week DAA cure, with the exception of patient with decompensated cirrhosis receiving also 12 weeks of ribavirin [27, 
$28]$, leading to a total cost of $29,615 €$. In the baseline analysis, we did not consider any cost related to treatment-related adverse events. This was varied in sensitivity analysis.

\section{Health-related quality of life}

EuroQol-5D was used to evaluate health utility in CHC patients with use of French TimeTrade-Off value set: 0.82 when fibrosis $\leq \mathrm{F} 2$ and 0.76 when fibrosis F3-4 prior treatment, 0.60 for decompensated and HCC patients, 0.55 for the first year and 0.82 for subsequent years after liver transplantation (Supplementary Material) [29]. Health utilities were increased to 0.95 and 0.85 after SVR for F0-1 and for F2-4, respectively, as observed in Adelphi study [30]. Health utilities were remained unchanged after SVR in decompensated cirrhosis.

\section{Sensitivity analysis}

An extensive sensitivity analysis was conducted to evaluate the impact of assumptions or uncertainties around the data on the cost-effectiveness analysis considering only the case of treatment for all, and to determine the robustness of our overall conclusions (Supplementary Material). Firstly, we performed a one-way deterministic sensitivity analysis, varying values of input parameters that may change our conclusions. In order to take into account the limits of the utility data set used, we also conducted the analysis from Canadian data often cited in the literature and based on Euro-Qol-5D [31]. We also changed the distribution of the study population - i.e. the French general population aged 18 to 80 years, without any known diagnosis of HCV-RNA positivity - according to gender and age-group, so as the gender- and age-distribution of undiagnosed chronically-infected $\mathrm{HCV}$ population to be consistent with estimates of Brouard et al [3]. We also performed an analysis considering costs related to severe anemia leading to transfusion for patients initiating ribavirin. Finally, we considered a 
delay of one year after diagnosis before treatment initiation. Secondly, we performed probabilistic sensitivity analysis using 1000 second-order samples of the parameters (Supplementary Material).

\section{Software}

The model was analyzed with TreeAge Pro 2017 suite software (Williamstown, MA, USA). 


\section{Results}

\section{Baseline analysis}

When considering treatment initiation to patients with fibrosis stage $\geq F 2$, CHC prevalence among the 18-80 undiagnosed general population decreased after a year from $0.23 \%$ to 0.17 $0.21 \%$ according to the strategy, and to $0.12-0.20 \%$ when considering treatment for all, i.e. regardless of fibrosis stage (Fig. 1.).

Fig. 2. reported effectiveness results of the different HCV screening strategies in terms of cumulated incidence of cirrhosis F4, decompensated cirrhosis, HCC and liver-related deaths among CHC population after 10 (Fig. 2A.) and 20 years (Fig. 2B.). The most effective strategy is universal screening of individuals between 18 and 80 years leading to the lowest incidences of events: as an example, $2.36 \%$ for cirrhosis, $1.92 \%$ for decompensated cirrhosis, $2.34 \%$ for HCC and $5.28 \%$ for liver deaths after 20 years, compared to $3.03 \%, 2.29 \%, 2.54 \%$ and 5.76\%, respectively, with the current strategy (risk-based).

Table 3 reported results of the cost-effectiveness baseline analysis of different HCV screening strategies. Either by initiating DAAs combination to patients with fibrosis stage $\geq F 2$ or regardless of fibrosis, the current strategy was the cheapest but also the least effective. When treatment was initiated to patients with fibrosis stage $\geq F 2$, adding the screening of all people aged 40-59 years or of all men between 18 and 59 years was dominated. Targeting all people aged 40-80 was the only cost-effective strategy at both WTP thresholds (€26,100 per QALY gained), leading to save an average of 0.05 LYs and 0.05 QALYs among CHC patients compared to the current strategy. Universal screening was the most effective strategy leading to save among CHC patients an average of 0.06 LYs and 0.07 QALYs compared to the current strategy. However this strategy was not cost-effective (€147,200 per QALY gained). When we considered treatment for all (Fig. 3A.), adding all men aged 18-59 years to the 
current screening strategy was dominated. Targeting all people aged 40-80 was associated with the lowest ICER $(21,400 € /$ QALY) leading this strategy to be cost-effective at both WTP thresholds. Although associated to the highest costs, universal screening was even more effective than targeting all people 40-80 and remained cost-effective (31,100€/QALY) at both WTP thresholds.

\section{Sensitivity analysis}

During deterministic cost-effectiveness analysis, when we considered treatment for all, varying values of input parameters or assumptions did not affect our main results (Supplementary Tables 7-22), with some exceptions. First, when we changed utility data, universal strategy was no more cost-effective at a WTP of one time GDP per capita but remained cost-effective strategy at a WTP of three times GDP per capita (ICER at 59,200€/QALY compared to the strategy targeting all people 40-80) (Table 4). By contrast, when we varied the post-SVR utility gains and assumed no benefit, universal screening strategy was no more cost-effective (Table 4). Second, when we varied the assumption regarding the immediate initiation of treatment after diagnosis, considering a delay of one year after diagnosis before treatment initiation, universal screening is again the most effective but no more cost-effective (Table 5). Adding all men aged 18-59 to current screening strategy becomes the only cost-effective strategy at both WTP (ICER at 32,800€/QALY compared to the current strategy). Third, when we increased cost of screening tests by $20 \%$, universal screening remained cost-effective at a WTP of three times GDP per capita but no more costeffective at a WTP of one time GDP per capita (ICER at 36,300€/QALY compared to the strategy targeting all people 40-80) (Supplementary Table 15). Moreover, when we combined an increase in screening uptake from $50 \%$ to $100 \%$ and in cost of screening tests from $0 \%$ to 
$20 \%$, the average lifetime cost for universal screening increased from 84.92 to $100.24 €$ per person and ICER increased from 31,100 to 36,700€/QALY compared to the strategy targeting all 40-80 (Supplementary Table 22). Again, universal screening remained cost-effective over the entire range of variation at a WTP of one time GDP per capita or slightly above that threshold while being below the threshold of three times GDP per capita. Finally, when we changed the distribution of the study population, universal strategy was again no more costeffective at a WTP of one time GDP per capita but remained cost-effective strategy at a WTP of three times GDP per capita (ICER at 54,500€/QALY compared to the strategy targeting all people 40-80) (Supplementary Table 20).

Using probabilistic sensitivity analysis, we estimated that universal screening was costeffective with $24 \%$ probability at a WTP of one time GDP per capita and $68 \%$ probability at a WTP of three times GDP per capita (Fig. 3B.). 


\section{Discussion}

This study evaluated the effectiveness, cost and cost-effectiveness of different HCV screening strategies in France. First, current screening based on risk-factors was associated to the lowest life expectancy and QALYs. Second, adding the screening of individuals with specific age and/or gender to the current strategy increased effectiveness but also costs. Universal screening was associated to the highest life expectancy and QALYs but was not cost-effective under the scenario of initiating treatment to individuals with fibrosis stage $\geq F 2$; the only costeffective strategy being the addition of all individuals aged 40-80 to the current strategy under this scenario whether considering a WTP of three or one times GDP per capita. However, when we considered the treatment for all scenario, universal screening was associated to the highest effectiveness and became a cost-effective strategy at both thresholds, compared to the addition of all individuals aged 40-80.

Our study was conducted following the first French report for recommendations on the management of patients with hepatitis C or B virus [32]. Given the limits reached by the current screening strategy based on risk factors, an expert panel was established in France to develop new recommendations for HCV testing [33]. Data of HCV-undiagnosed people from the 2004 seroprevalence survey [2] showed that $55 \%$ of all of HCV undiagnosed people in 2004 are men aged 18-59 years [3]. The proportion of HIV and HBV undiagnosed patients who were men were even higher. Based on these considerations, and also to facilitate implementation of the general population screening in particular among general practitioner, the expert panel recommended first targeting all men aged 18-59 years at least once in their life as a complement to current risk-based testing and considering jointly $\mathrm{HBV}, \mathrm{HCV}$ and HIV [32]. Our cost-effectiveness analysis for HCV screening showed indeed that this population-based screening strategy would be more effective than the current one. However 
we also found that universal screening would be even more effective. Cost-effectiveness results were in part related on utility data and on whether treatment would be initiated at stage of fibrosis $\geq$ F2 or regardless of fibrosis stage. Indeed the cost-effectiveness of a screening strategy is strongly linked to the stage of the disease at the time of treatment initiation. Universal screening is cost-effective if treatment is started at an early stage of infection but is no longer effective if treatment is started in advances stages of fibrosis. Also, when considering one year between diagnosis and treatment initiation, universal screening was no more cost-effective. This can be explained by a higher loss of effectiveness especially in older individuals when compared to a strategy targeting a younger population, while the cost of the universal screening remained higher. This means that a recommendation for a universal screening strategy must be accompanied by a recommendation for rapid initiation of treatment for all. Based on these results, the most recent French recommendations call for extending HCV screening to all adults [15]. However, in France, it is the Haute Authorité de la Santé that enlightens public authorities on decisions of recommendations and refund of the medical products and services. To date, the HAS has not changed its recommendations for hepatitis C screening but is currently considering our study in light of future recommendations. We can expect a decision in favor of universal screening, in addition to the reinforcement of targeted testing, as has been done for HIV [34].

These discrepancies between cost-effectiveness results when we concern different treatment initiation criteria can be explained as follow. When considering targeted treatment to fibrosis stage $\geq F 2$, adding the screening of all individuals aged 40-80 to the current strategy would be effective and the only cost-effective strategy, for at least two combined reasons. First, it led to reach age classes with the highest $\mathrm{CHC}$ prevalence; namely those over 60 years of age [3]. Second, adding the screening of all individuals aged 40-80 to the current strategy allowed optimizing the screening of those that would be eligible for therapy. Indeed, the large majority 
of patients aged 18-39 are in fibrosis stage F0F1 and are not eligible (Supplementary Table 3) [23]. As a result screening of these patients if treatment is not initiated immediately is less interesting. By contrast, when considering treatment for all with IFN-free DAA-based regimen as it is now implemented in France, universal screening became also a cost-effective strategy and was the most effective one.

Outside France, HCV screening was extended to birth cohorts in 2012 in the US. Since the highest incidence of HCV was found in people born between the years 1945-1965, both the CDC and the United States public health task force recommended one-time testing for antiHCV for people born within this two decade period $[8,35]$. Indeed, this strategy was found to be cost-effective at $\$ 35,700$ per QALY compared to risk-based strategy when considering treatment with interferon-based DAAs after screening [36]. Alternative evaluations confirmed that broader screening for HCV (1945-1965 or 1946-1970 birth-cohorts, general population aged 20-69 years) was cost-effective in the US compared to risk-based [37-40], and emphasized that screening only high-risk birth cohorts may be more cost-effective than screening the general population [38]. One main difference with our study is that those analyses conducted in the USA considered either dual therapy with peginterferon and ribavirin or triple therapy adding a protease inhibitor whom efficacy was lower and side effects higher than current IFN-free DAAs. They also emphasized that the benefits of screening increased with increasing treatment eligibility and efficacy. More recent costeffectiveness evaluations were conducted in the US showing that universal screening was more cost-effective than the current birth cohort recommendations [41, 42]. In Canada, when treating with past dual or triple therapy, screening of the general population was only found to be cost-effective in targeting sub-populations with high HCV prevalence [43]. Even if a more recent analysis suggested that a selective one-time HCV screening program for people 25-64 would likely be cost-effective [44], the Canadian Task Force on Preventive Health Care 
recommended testing only individuals at elevated risk of $\mathrm{HCV}$ arguing that the $\mathrm{HCV}$ prevalence in the general Canadian population is low $(0.8 \%$, i.e. four times lower than in the US in 1945-1965 birth cohorts) and direct evidence examining the benefits and harms of general screening for $\mathrm{HCV}$ is not available [45].

Our work has some limitations. First, we used a mathematical model relying on input data from multiple sources. Second, our baseline analysis was based on limited data for healthrelated utility, in particular regarding the utility benefit from achieving SVR. Using an alternative utility data set often cited in the literature [31], universal strategy remained costeffective at a WTP between one to three times GDP per capita. However, it was no longer considering no utility benefit from achieving SVR, which seems unlikely [46]. Third, once $\mathrm{CHC}$ diagnosed, treatment was initiated either to patients with fibrosis stage $\geq \mathrm{F} 2$ or regardless of fibrosis, assuming a perfect linkage-to care of diagnosed individuals. However, varying proportion of treatment initiation between 50 and $100 \%$ did not affect our main results. Fourth, we based our model of the last French seroprevalence survey reflecting the year 2004 . We took into account that this population may have changed given the evolution of HCV screening and HCV-RNA prevalence among undiagnosed individuals. However, again, we have varied our assumptions and universal strategy remained cost-effective at a WTP between one to three times GDP per capita. Fifth, as a conservative assumption, we based our analyses on listed prices of drugs. It is common that negotiated real prices are often lower, but these prices are unknown. It means that universal screening with treatment for all may be even more cost-effective. Sixth, conservatively again, we did not consider the impact of treatments on comorbidities and the possible reduction of the competitive mortality after SVR as well as the reduction of HCV transmission following HCV screening and treatment. Cousien et al illustrated the high effectiveness and cost-effectiveness of improving both testing and linkage to care together with a universal treatment in reducing $\mathrm{HCV}$ transmission in people who inject 
drugs [47]. It means that universal screening should be even more cost-effective when considering its impact of HCV transmission. Finally, this work was based on French data and the French health system, but can be adapted to other countries.

In conclusion, in France, when considering treatment for all, universal screening of all individuals $18-80$ is the most effective and a cost-effective strategy. From an individual and especially from a societal perspective of $\mathrm{HCV}$ eradication, this strategy should be certainly implemented. However, when recommending such strategy, rapid initiation of treatment after diagnosis is required. 


\section{References}

[1] European Centre for Disease Prevention and Control. Hepatitis B and C in the EU neighbourhood: prevalence, burden of disease and screening policies. Stockholm: ECDC; 2010.

[2] Meffre C, Le Strat Y, Delarocque-Astagneau E, Dubois F, Antona D, Lemasson JM, et al. Prevalence of hepatitis B and hepatitis C virus infections in France in 2004: social factors are important predictors after adjusting for known risk factors. J Med Virol 2010;82:546-555. [3] Brouard C, Le Strat Y, Larsen C, Jauffret-Roustide M, Lot F, Pillonel J. The undiagnosed chronically-infected HCV population in France. Implications for expanded testing recommendations in 2014. PLoS One 2015;10:e0126920.

[4] Delarocque-Astagneau E, Meffre C, Dubois F, Pioche C, Le Strat Y, Roudot-Thoraval F, et al. The impact of the prevention programme of hepatitis $C$ over more than a decade: the French experience. J Viral Hepat 2010;17:435-443.

[5] Brouard C, Delarocque Astagneau E, Meffre C, Pioche C, Silvain C, Larsen C, et al. Trends of hepatitis C screening in France through Rena-VHC and hepatology reference centres surveillance system, 2000-2007. Bull Epidemiol Hebd 2009;20-21:199-204.

[6] Arends JE, Kracht PA, Hoepelman AI, on behalf of the European Study Group for Viral Hepatitis (ESGVH). Performance of hepatitis C virus (HCV) direct-acting antivirals in clinical trials and daily practice. Clin Microbiol Infect 2016;22:846-852.

[7] Chevaliez S, Poiteau L, Rosa I, Soulier A, Roudot-Thoraval F, Laperche S, et al. Prospective assessment of rapid diagnostic tests for the detection of antibodies to hepatitis $\mathrm{C}$ virus, a tool for improving access to care. Clin Microbiol Infect 2016;22:459 e451-456.

[8] Smith BD, Morgan RL, Beckett GA, Falck-Ytter Y, Holtzman D, Ward JW. Hepatitis C virus testing of persons born during 1945-1965: recommendations from the Centers for Disease Control and Prevention. Ann Intern Med 2012;157:817-822. 
[9] Grebely J, Bilodeau M, Feld JJ, Bruneau J, Fischer B, Raven JF, et al. The Second

Canadian Symposium on hepatitis C virus: a call to action. Canadian Journal of Gastroenterology 2013;27:627-632.

[10] Canadian Liver Foundation. Position statement - hepatitis C testing; 2012.

[11] Deuffic-Burban S, Deltenre P, Buti M, Stroffolini T, Parkes J, Muhlberger N, et al. Predicted effects of treatment for HCV infection vary among European countries.

Gastroenterology 2012;143:974-985 e914.

[12] Deuffic-Burban S, Boursier J, Leroy V, Yazdanpanah Y, Castera L, Mathurin P. Are targeted treatment recommendations in chronic hepatitis $\mathrm{C}$ tailored to diagnostic methods of fibrosis? J Hepatol 2017;66:304-312.

[13] Schwarzinger M, Deuffic-Burban S, Mallet V, Pol S, Pageaux GP, Canva-Delcambre V, et al. Lifetime costs attributable to chronic hepatitis C from the French healthcare perspective (Anrs N¹2188). J Hepatol 2013;58:S21-22.

[14] Cousien A, Tran VC, Deuffic-Burban S, Jauffret-Roustide M, Dhersin JS, Yazdanpanah Y. Hepatitis C treatment as prevention of viral transmission and liver-related morbidity in persons who inject drugs. Hepatology 2016;63:1090-1101.

[15] Prise en charge thérapeutique et suivi de l'ensemble des personnes infectées par le virus de l'hépatite C. Rapport de recommandations 2016: Sous la direction du Pr Daniel Dhumeaux. Sous l'égide de l'ANRS et du CNS et avec le concours de l'AFEF.

[16] Gold MR, Siegel JE, Russell LB, Weinstein MC. Cost effectiveness in health and medicine. New-York: Oxford University Press; 1996.

[17] HAS Haute Autorité de Santé. Guide méthodologique : Choix méthodologiques pour l'évaluation économique à la HAS. Octobre 2011: Haute Autorité de Santé; 2011.

[18] Index mundi. World GDP - per capita (PPP). [cited 12 February 2018]; Available from: https://www.indexmundi.com/world/gdp_per_capita_(ppp).html 
[19] WHO. Making choices in health: WHO guide to cost-effectiveness analysis. Geneva: WHO; 2003.

[20] Neumann PJ, Cohen JT, Weinstein MC. Updating cost-effectiveness--the curious resilience of the \$50,000-per-QALY threshold. N Engl J Med 2014;371:796-797.

[21] Deuffic-Burban S, Obach D, Canva V, Pol S, Roudot-Thoraval F, Dhumeaux D, et al. Cost-effectiveness and budget impact of interferon-free direct-acting antiviral-based regimens for hepatitis C treatment: the French case. J Viral Hepat 2016;23:767-779.

[22] Corrao G, Arico S. Independent and combined action of hepatitis C virus infection and alcohol consumption on the risk of symptomatic liver cirrhosis. Hepatology 1998;27:914-919. [23] Deuffic-Burban S, Mathurin P, Pol S, Larsen C, Roudot-Thoraval F, Desenclos JC, et al. Impact of hepatitis $\mathrm{C}$ triple therapy availability upon the number of patients to be treated and associated costs in France: a model-based analysis. Gut 2012;61:290-296.

[24] European Association for the Study of the Liver. EASL Recommendations on Treatment of Hepatitis C 2016. J Hepatol 2017;66:153-194.

[25] van der Meer AJ, Veldt BJ, Feld JJ, Wedemeyer H, Dufour JF, Lammert F, et al. Association between sustained virological response and all-cause mortality among patients with chronic hepatitis C and advanced hepatic fibrosis. JAMA 2012;308:2584-2593.

[26] Deuffic-Burban S, Schwarzinger M, Obach D, Mallet V, Pol S, Pageaux GP, et al. Should we await IFN-free regimens to treat HCV genotype 1 treatment-naive patients? A cost-effectiveness analysis (ANRS 95141). J Hepatol 2014;61:7-14.

[27] AFEF. Recommandations AFEF sur la prise en charge de l'hépatite virale C: Société Française d'Hépatologie; 2017 Mars 2017.

[28] Ministère des Affaires sociales et de la Santé. Accès universel aux traitements innovants contre l'hépatite $\mathrm{C}:$ Après avoir permis l'accès de tous les malades aux traitements, Marisol Touraine obtient une baisse de prix importante. Paris. 
[29] Chevalier J, de Pouvourville G. Valuing EQ-5D using time trade-off in France. Eur J Health Econ 2013;14:57-66.

[30] Pol S, Chevalier J, Branchoux S, Perry R, Milligan G, Gaudin A-F. Health related quality of life and utility values in chronic hepatitis $\mathrm{C}$ patients: A cross-sectional study in France, the Uk and Germany (P0747). J Hepatol 2015;62:S606.

[31] Chong CA, Gulamhussein A, Heathcote EJ, Lilly L, Sherman M, Naglie G, et al. Health-state utilities and quality of life in hepatitis C patients. Am J Gastroenterol 2003;98:630-638.

[32] Prise en charge des personnes infectées par les virus de l'hépatite B ou de l'hépatite C. Rapport de recommandations 2014: Sous la direction du Pr Daniel Dhumeaux et sous l'égide de l'ANRS et de l'AFEF.

[33] Bottero J, Brouard C, Roudot-Thoraval F, Deuffic-Burban S, Hofliger P, Abergel A, et al. 2014 French guidelines for hepatitis B and C screening: a combined targeted and mass testing strategy of chronic viruses namely HBV, HCV and HIV. Liver Int 2016;36:1442-1449. [34] Synthèse de la recommandation en santé publique - Réévaluation de la stratégie de dépistage de l'infection à VIH en France - Mars 2017. [cited April 3, 2018]; Available from: https://www.has-sante.fr/portail/upload/docs/application/pdf/2017-

\section{3/dir2/reevaluation_de_la_strategie_depistage_vih___synthese_reco.pdf}

[35] Moyer VA, U. S. Preventive Services Task Force. Screening for hepatitis C virus infection in adults: U.S. Preventive Services Task Force recommendation statement. Ann Intern Med 2013;159:349-357.

[36] Rein DB, Smith BD, Wittenborn JS, Lesesne SB, Wagner LD, Roblin DW, et al. The cost-effectiveness of birth-cohort screening for hepatitis C antibody in U.S. primary care settings. Ann Intern Med 2012;156:263-270. 
[37] McGarry LJ, Pawar VS, Panchmatia HR, Rubin JL, Davis GL, Younossi ZM, et al. Economic model of a birth cohort screening program for hepatitis $\mathrm{C}$ virus. Hepatology 2012;55:1344-1355.

[38] Coffin PO, Scott JD, Golden MR, Sullivan SD. Cost-effectiveness and population outcomes of general population screening for hepatitis C. Clin Infect Dis 2012;54:1259-1271. [39] Liu S, Cipriano LE, Holodniy M, Goldhaber-Fiebert JD. Cost-effectiveness analysis of risk-factor guided and birth-cohort screening for chronic hepatitis $\mathrm{C}$ infection in the United States. PLoS One 2013;8:e58975.

[40] McEwan P, Ward T, Yuan Y, Kim R, L'Italien G. The impact of timing and prioritization on the cost-effectiveness of birth cohort testing and treatment for hepatitis $\mathrm{C}$ virus in the United States. Hepatology 2013;58:54-64.

[41] Rein DB, Wittenborn JS, Dougherty MC. The Cost-effectiveness of a one time hepatitis $\mathrm{C}$ virus antibody test followed by treatment for all Americans ages 18 and older as compared to current testing recommendations in the United States. J Hepatol 2017;66 suppl:S405.

[42] Barocas JA, Tasillo A, Eftekhari Yazdi G, Wang J, Vellozzi C, Hariri S, et al. Population level outcomes and cost-effectiveness of expanding the recommendation for agebased hepatitis C testing in the United States. Clin Infect Dis 2018.

[43] Eckman MH, Talal AH, Gordon SC, Schiff E, Sherman KE. Cost-effectiveness of screening for chronic hepatitis C infection in the United States. Clin Infect Dis 2013;56:13821393.

[44] Wong WW, Tu HA, Feld JJ, Wong T, Krahn M. Cost-effectiveness of screening for hepatitis C in Canada. CMAJ 2015;187:E110-121.

[45] Canadian Task Force on Preventive Health C. Recommendations on hepatitis C screening for adults. CMAJ 2017;189:E594-E604. 
[46] Dusheiko G. The impact of antiviral therapy for hepatitis $\mathrm{C}$ on the quality of life: a perspective. Liver Int 2017;37 Suppl 1:7-12.

[47] Cousien A, Tran VC, Deuffic-Burban S, Jauffret-Roustide M, Mabileau G, Dhersin JS, et al. Effectiveness and cost-effectiveness of interventions targeting harm reduction and chronic hepatitis C cascade of care in people who inject drugs; the case of France. J Viral Hepat 2018. 
Table 1 - Characteristics of the study population $[2,3]$

\begin{tabular}{|c|c|c|c|c|}
\hline & \multirow{2}{*}{$\begin{array}{l}\text { Repartition by } \\
\text { gender and age (\%) }\end{array}$} & \multirow{2}{*}{$\begin{array}{l}\text { Proportion at } \\
\text { high risk* }(\%)\end{array}$} & \multicolumn{2}{|c|}{ Proportion of HCV-RNA positive (\%)* } \\
\hline & & & High risk $\dagger$ & Low risk $\dagger$ \\
\hline \multicolumn{5}{|l|}{ Males } \\
\hline $18-39$ & 20.78 & 39.80 & 0.173 & 0.188 \\
\hline $40-59$ & 17.29 & 68.50 & 0.131 & 0.165 \\
\hline $60-80$ & 10.64 & 73.30 & 0.212 & 0.921 \\
\hline \multicolumn{5}{|c|}{ Females } \\
\hline $18-39$ & 20.75 & 52.10 & 0.030 & 0.003 \\
\hline $40-59$ & 17.50 & 79.30 & 0.219 & 0.073 \\
\hline $60-80$ & 13.05 & 83.20 & 0.775 & 0.299 \\
\hline
\end{tabular}

*The corresponding distribution of HCV-RNA positive among the whole study population was: males, $16.25 \%$ (18-39), $10.52 \%$ (40-59), $18.34 \%$ (60-80); females, $1.52 \%$ (18-39), $14.11 \%$ (40-59), 39.26\% (60-80). $†$ High risk corresponded to the presence of risk factors as defined in supplementary Table S2; low risk to the absence. 
Table 2 - Data on the proportion of screened individuals according to each strategy $[2,3]$

\begin{tabular}{|c|c|c|c|c|c|c|}
\hline \multirow[b]{2}{*}{ Strategy } & \multicolumn{3}{|c|}{ Males } & \multicolumn{3}{|c|}{ Females } \\
\hline & $18-39$ & $40-59$ & $60-80$ & $18-39$ & $40-59$ & $60-80$ \\
\hline \multicolumn{7}{|l|}{ Low risk* } \\
\hline $\mathrm{S} 1=$ risk-based & $16 \%$ & $16 \%$ & $6 \%$ & $18 \%$ & $18 \%$ & $4 \%$ \\
\hline $\mathrm{S} 2=\mathrm{S} 1+$ all men aged 18 to 59 years & $50 \%$ & $50 \%$ & $6 \%$ & $18 \%$ & $18 \%$ & $4 \%$ \\
\hline $\mathrm{S} 3=\mathrm{S} 1+$ all individuals aged 40 to 59 years & $16 \%$ & $50 \%$ & $6 \%$ & $18 \%$ & $50 \%$ & $4 \%$ \\
\hline $\mathrm{S} 4=\mathrm{S} 1+$ all individuals aged 40 to 80 years & $16 \%$ & $50 \%$ & $50 \%$ & $18 \%$ & $50 \%$ & $50 \%$ \\
\hline $\mathrm{S} 5=\mathrm{S} 1+$ all individuals aged 18 to 80 years & $50 \%$ & $50 \%$ & $50 \%$ & $50 \%$ & $50 \%$ & $50 \%$ \\
\hline \multicolumn{7}{|l|}{ High risk* } \\
\hline $\mathrm{S} 1=$ risk-based & $19 \%$ & $19 \%$ & $10 \%$ & $19 \%$ & $19 \%$ & $15 \%$ \\
\hline $\mathrm{S} 2=\mathrm{S} 1+$ all men aged 18 to 59 years & $50 \%$ & $50 \%$ & $6 \%$ & $18 \%$ & $18 \%$ & $4 \%$ \\
\hline $\mathrm{S} 3=\mathrm{S} 1+$ all individuals aged 40 to 59 years & $16 \%$ & $50 \%$ & $6 \%$ & $18 \%$ & $50 \%$ & $4 \%$ \\
\hline $\mathrm{S} 4=\mathrm{S} 1+$ all individuals aged 40 to 80 years & $16 \%$ & $50 \%$ & $50 \%$ & $18 \%$ & $50 \%$ & $50 \%$ \\
\hline $\mathrm{S} 5=\mathrm{S} 1+$ all individuals aged 18 to 80 years & $50 \%$ & $50 \%$ & $50 \%$ & $50 \%$ & $50 \%$ & $50 \%$ \\
\hline
\end{tabular}

*High risk corresponded to the presence of risk factors; low risk to the absence. 
Table 3 - Base case cost-effectiveness analysis of different HCV screening strategies according to treatment initiation when fibrosis stage $\geq \mathrm{F} 2$ or regardless of fibrosis stage.

\begin{tabular}{|c|c|c|c|c|}
\hline \multirow[t]{3}{*}{ Strategy } & QALY in the & QALY in the & Average & ICER* \\
\hline & study & HCV-RNA & lifetime cost & $(€ / Q A L Y)$ \\
\hline & population (a) & population & $(€)(\mathrm{c})$ & (c)/(a) \\
\hline
\end{tabular}

Treatment initiation when $\geq$ F2

$\begin{array}{lrrrr}\text { S1 }=\text { Risk-based strategy } & 21.306358 & 16.738040 & 66.69 & \\ \text { S3 = S1 and all 40-59 } & 21.306403 & 16.767182 & 68.78 & \text { Dominated }^{\dagger} \\ \text { S2 = S1 and all men 18-59 } & 21.306404 & 16.768116 & 69.09 & \text { Dominated }^{\dagger} \\ \text { S4 = S1 and all 40-80 } & 21.306520 & 16.791277 & 70.92 & 26,100 \\ \text { S5 }=\text { all 18-80 } & 21.306538 & 16.807824 & 73.57 & 147,200\end{array}$

Treatment initiation regardless of fibrosis

$\begin{array}{lrrrr}\text { S1 }=\text { Risk-based strategy } & 21.308202 & 18.019951 & 77.26 & \\ \text { S3 }=\text { S1 and all 40-59 } & 21.308268 & 18.061709 & 79.45 & \text { Dominated }^{\dagger} \\ \text { S2 }=\text { S1 and all men 18-59 } & 21.308336 & 18.090401 & 80.16 & \text { Dominated }^{\dagger} \\ \text { S4 }=\text { S1 and all 40-80 } & 21.308413 & 18.099513 & 81.78 & 21,400 \\ \text { S5 }=\text { all 18-80 } & 21.308514 & 18.176948 & 84.92 & 31,100\end{array}$

"The comparator for each ICER is the previous least costly strategy; ${ }^{*}$ weakly dominated strategy: higher ICER than that of a more effective alternative strategy. 
Table 4 - Sensitivity analysis considering either alternative utility data set [31], or no utility benefit from achieving SVR: cost-effectiveness analysis with treatment initiation regardless of fibrosis stage.

\begin{tabular}{|c|c|c|c|c|}
\hline \multirow[t]{2}{*}{ Strategy } & $\begin{array}{l}\text { QALY in the } \\
\text { study }\end{array}$ & $\begin{array}{l}\text { QALY in the } \\
\text { HCV-RNA }\end{array}$ & $\begin{array}{r}\text { Average } \\
\text { lifetime cost }\end{array}$ & $\begin{array}{r}\text { ICER }^{*} \\
(€ / \mathrm{OALY})\end{array}$ \\
\hline & population (a) & population & $(€)(\mathrm{c})$ & (c)/(a) \\
\hline \multicolumn{5}{|l|}{ Alternative utility data set } \\
\hline S1 = Risk-based strategy & 21.305749 & 16.415394 & 77.26 & \\
\hline $\mathrm{S} 3=\mathrm{S} 1$ and all $40-59$ & 21.305802 & 16.448852 & 79.45 & Dominated $^{\dagger}$ \\
\hline $\mathrm{S} 2=\mathrm{S} 1$ and all men $18-59$ & 21.305832 & 16.465998 & 80.16 & Dominated $^{\dagger}$ \\
\hline $\mathrm{S} 4=\mathrm{S} 1$ and all $40-80$ & 21.305927 & 16.473978 & 81.78 & 25,400 \\
\hline $\mathrm{S} 5=$ all $18-80$ & 21.305980 & 16.520117 & 84.92 & 59,200 \\
\hline
\end{tabular}

No utility benefit from SVR

$\begin{array}{lrrrr}\text { S1 }=\text { Risk-based strategy } & 21.304837 & 16.047927 & 77.26 & \\ \text { S3 = S1 and all 40-59 } & 21.304874 & 16.071941 & 79.45 & \text { Dominated }^{\dagger} \\ \text { S2 = S1 and all men 18-59 } & 21.304882 & 16.089423 & 80.16 & \text { Dominated }^{\dagger} \\ \text { S4 = S1 and all 40-80 } & 21.304958 & 16.076145 & 81.78 & 37,400 \\ \text { S5 }=\text { all 18-80 } & 21.304979 & 16.109002 & 84.92 & 149,500\end{array}$

"The comparator for each ICER is the previous least costly strategy; "Weakly dominated strategy: higher ICER than that of a more effective alternative strategy. 
Table 5 - Sensitivity analysis considering a delay of one year after diagnosis before treatment initiation: cost-effectiveness analysis with treatment initiation regardless of fibrosis stage.

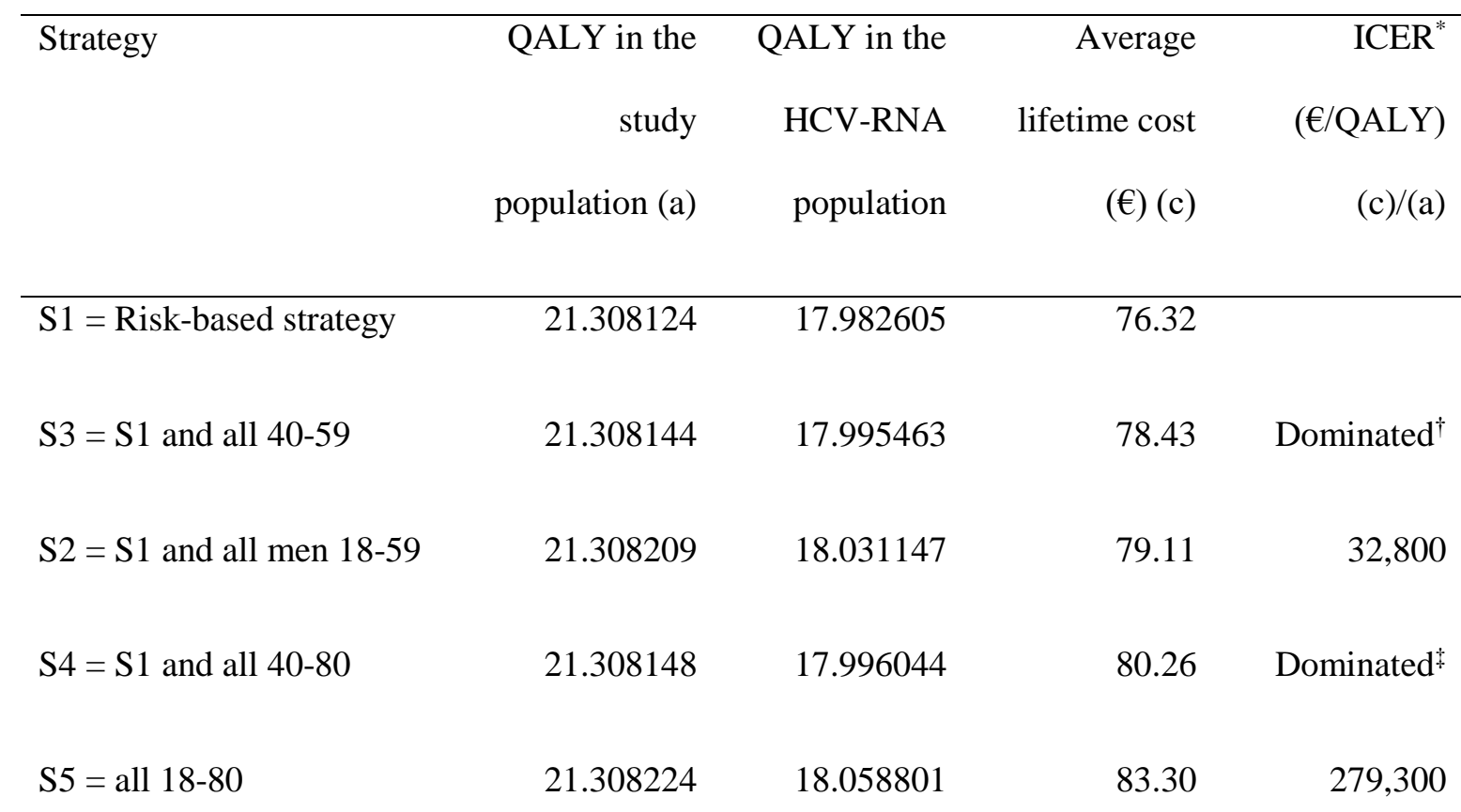

\footnotetext{
"The comparator for each ICER is the previous least costly strategy; 'Weakly dominated strategy: higher ICER than that of a more effective alternative strategy; "strongly dominated strategies: more expensive and less effective.
} 


\section{Figure legends}

Fig. 1. Predicted one-year CHC prevalence among the 18-80 French general population according to the screening strategy: base case analysis.

Fig. 2. Predicted cumulative incidence of cirrhosis (F4), decompensated cirrhosis,

hepatocellular carcinoma and liver deaths among $\mathrm{CHC}$ population after 10 (A) and 20 years (B): base case analysis.

Fig. 3. Cost-effectiveness analysis for the scenario considering treatment for all: (A)

Efficiency frontier; (B) Percentage of acceptability for each strategy by WTP threshold. 


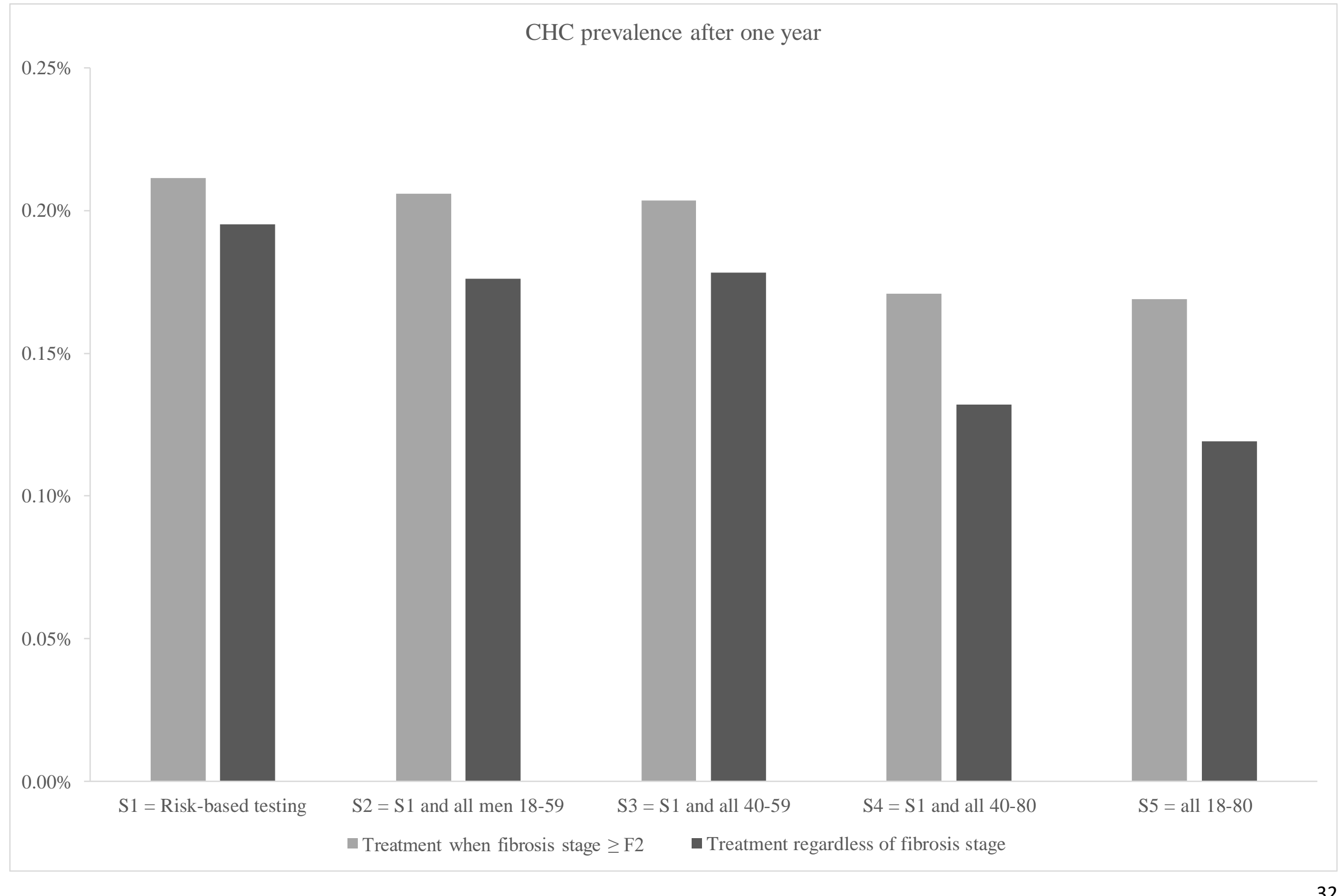




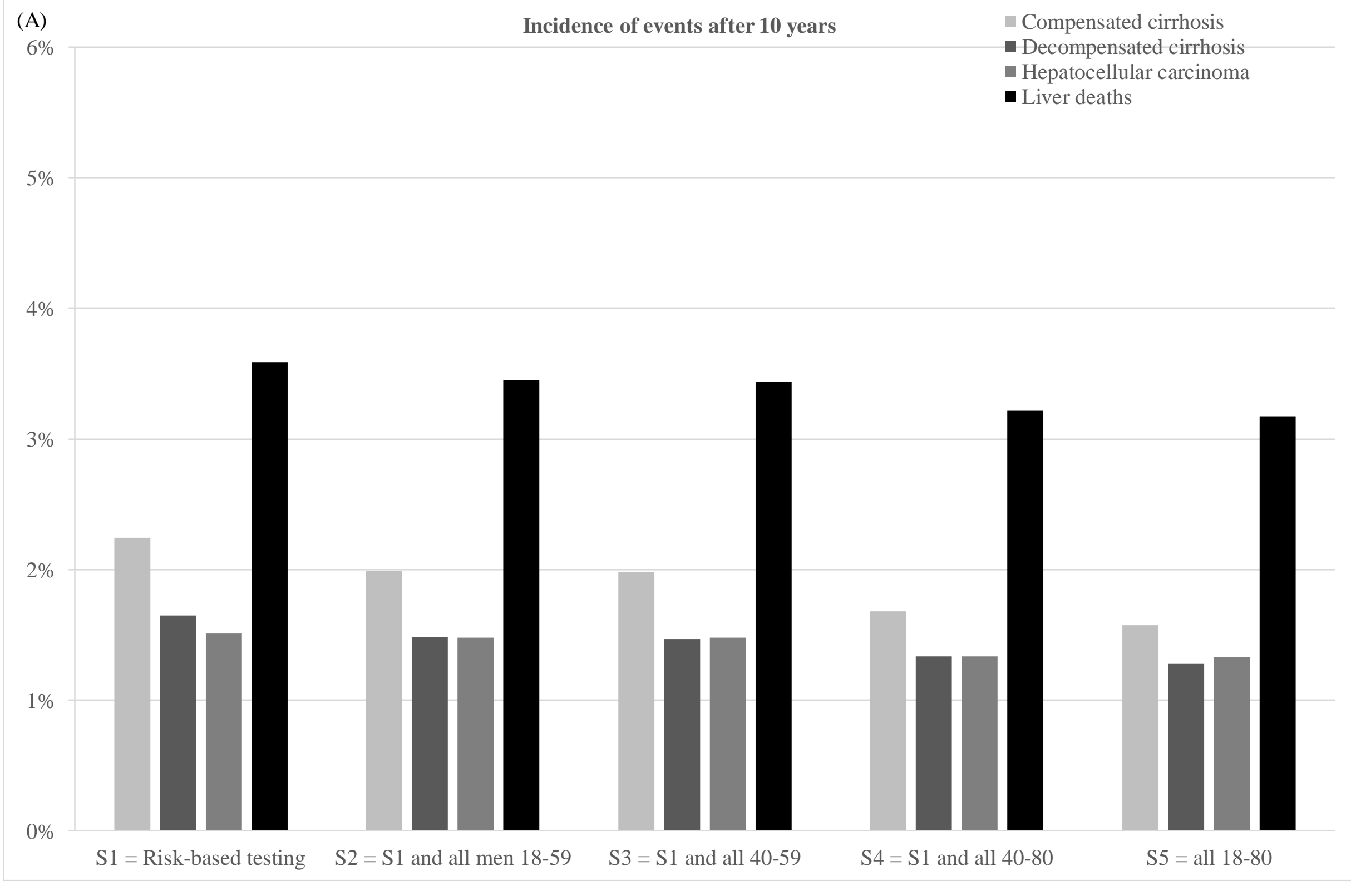




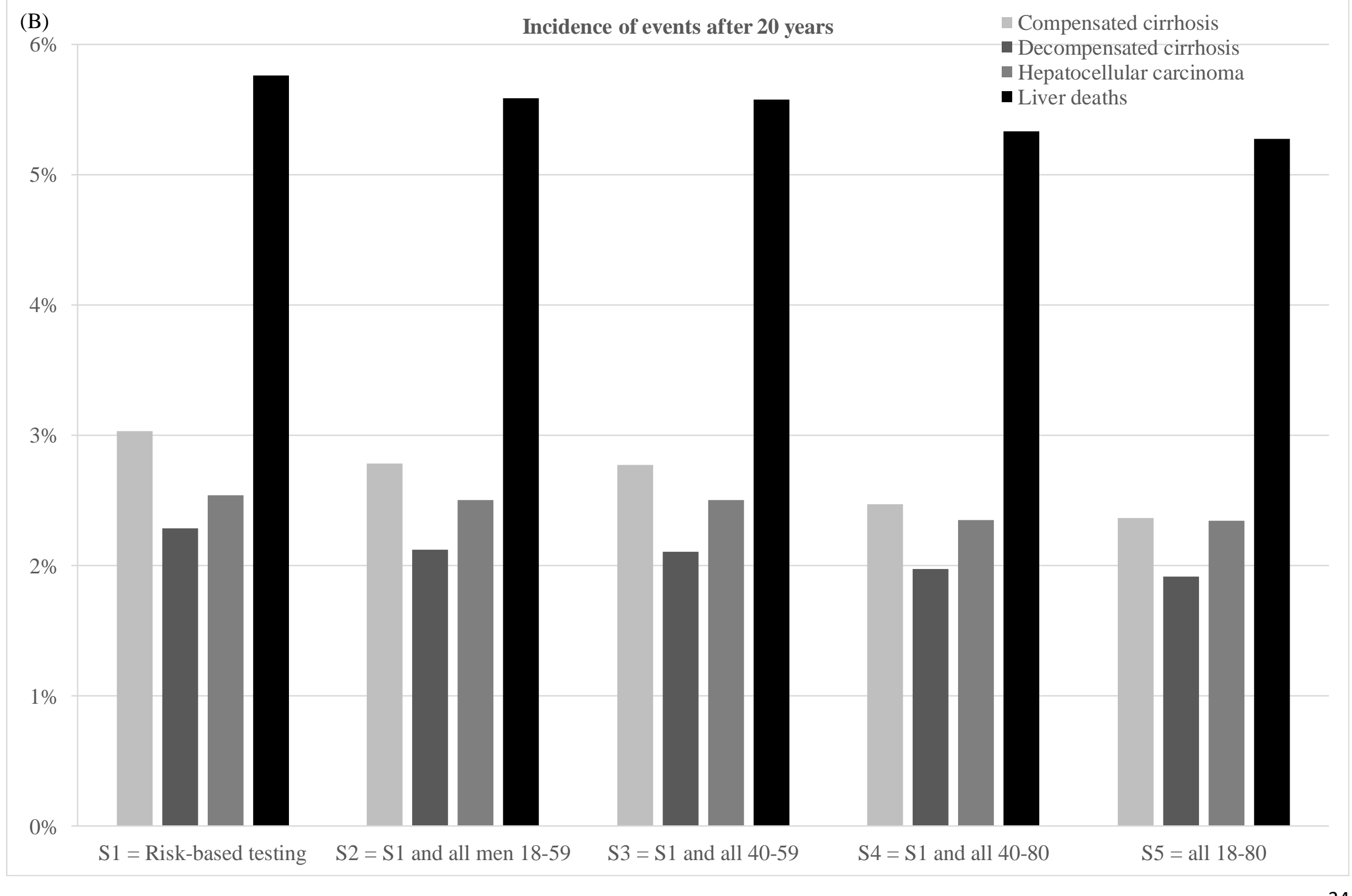




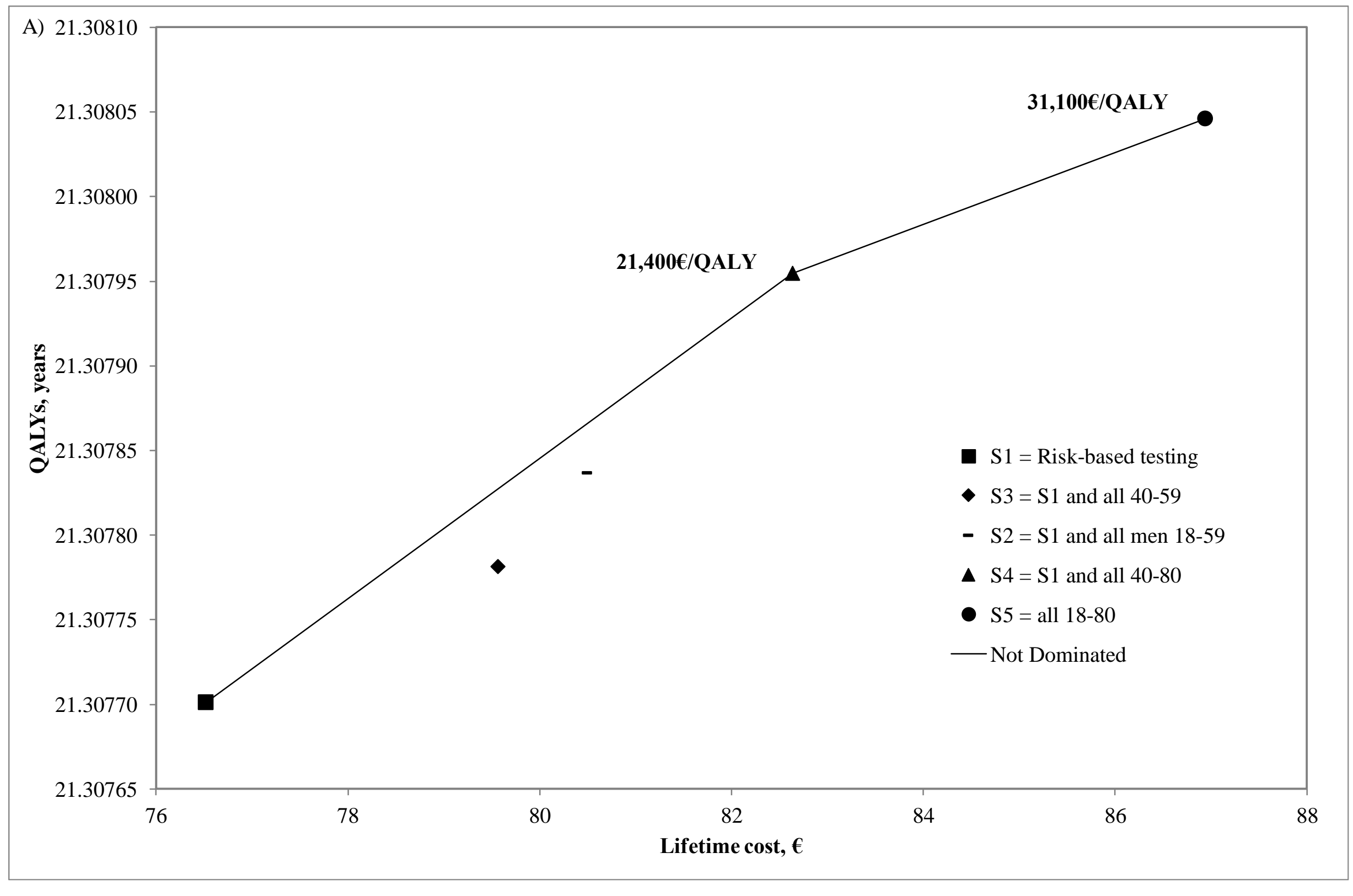




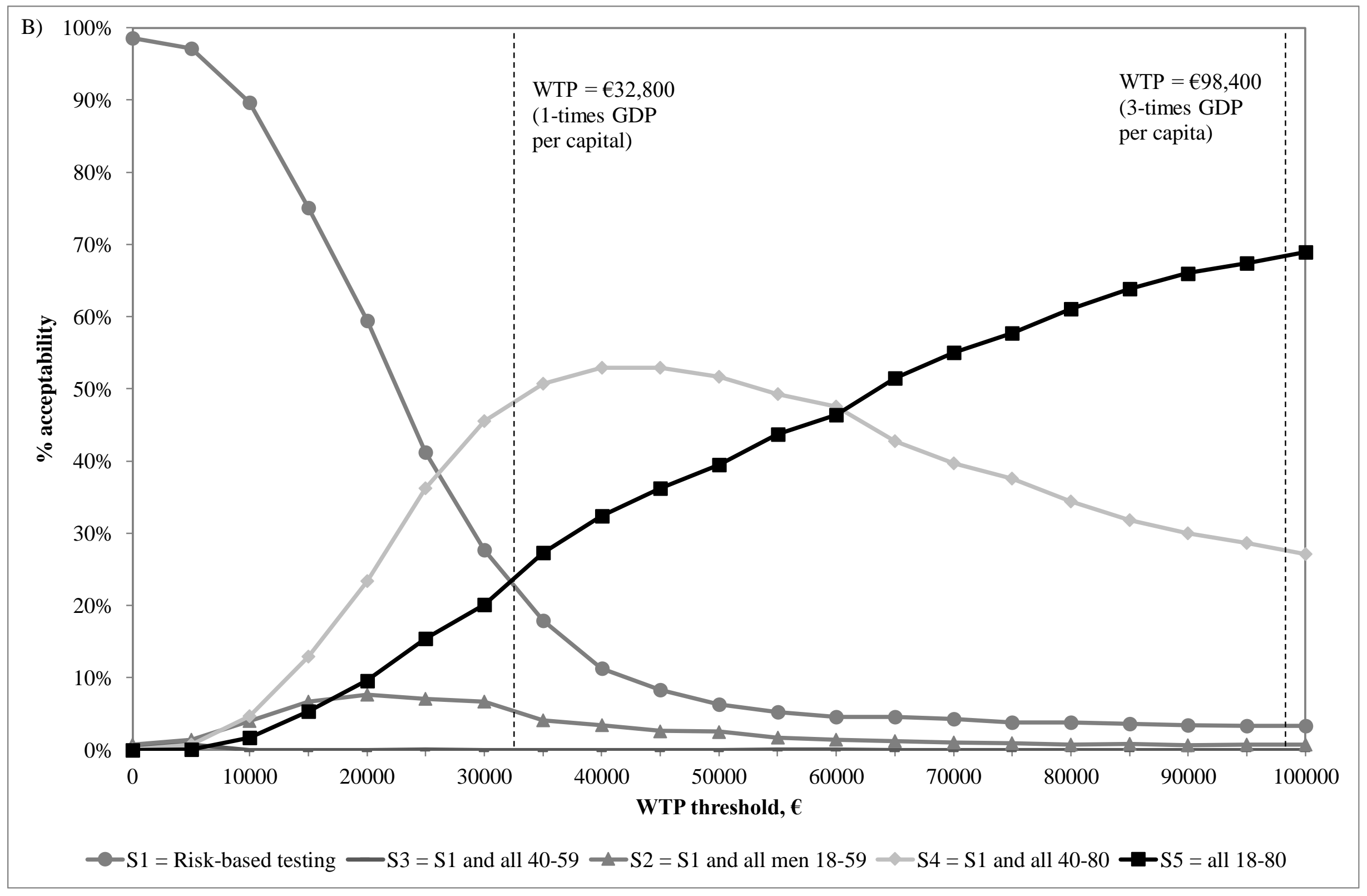




\section{Supplementary Material accompanying the manuscript titled "Assessing the cost- effectiveness of hepatitis C screening strategies in France"}

Sylvie Deuffic-Burban, Alexandre Huneau, Adeline Verleene, Cécile Brouard, Josiane

Pillonel, Yann Le Strat, Sabrina Cossais, Françoise Roudot-Thoraval, Valérie Canva, Philippe Mathurin, Daniel Dhumeaux, Yazdan Yazdanpanah

\section{Table of contents}

Natural history of chronic hepatitis C Erreur ! Signet non défini.

Study population 5

Cost data 7

Health-related quality of life 8

Sensitivity analysis

Figure S1. Model structure: a) Testing decision tree; b) Markov-based model of chronic hepatitis $\mathrm{C}$ progression. $\mathrm{OH}$ - corresponds to no alcohol abuse (0-50g/day), $\mathrm{OH}+$ corresponds to alcohol abuse (>50g/day).

Figure S2. Predicted cumulative incidence of cirrhosis (F4), decompensated cirrhosis, hepatocellular carcinoma and liver deaths among $\mathrm{CHC}$ population after 10 years (A) and 20 years (B): base case analysis.

Supplementary Table 1 - Parameters of progression of chronic hepatitis $\mathrm{C}(\mathrm{CHC})$ and impact of treatment on progression.

Supplementary Table 2 - French recommendations for HCV screening based on risk factors $[12,23]$

Supplementary Table 3 - Disease stage distribution according to gender, age and alcohol status, and average time until diagnosis [7]

Supplementary Table 4 - Annual costs (standard deviation) attributable to chronic hepatitis C: ambulatory costs (never-treated and after HCV treatment failure) and hospitalization costs (no death and in-hospital death) [24].....

Supplementary Table 5 - Health-related utilities

Supplementary Table 6 - Distribution used for each model input during probabilistic sensitivity analysis. 
Supplementary Table 7 - Sensitivity analysis varying the proportions of high-risk population by $\pm 20 \%$ : cost-effectiveness analysis with treatment initiation regardless of fibrosis stage .. 23

Supplementary Table 8 - Sensitivity analysis varying the proportions of HCV-RNA positivity by $\pm 20 \%$ : cost-effectiveness analysis with treatment initiation regardless of fibrosis stage .. 24

Supplementary Table 9 - Sensitivity analysis varying the proportions of excessive alcohol consumption by $\pm 20 \%$ : cost-effectiveness analysis with treatment initiation regardless of fibrosis stage.

Supplementary Table 10 - Sensitivity analysis varying the proportions of individuals reached by the current strategy by $\pm 20 \%$ : cost-effectiveness analysis with treatment initiation regardless of fibrosis stage 26

Supplementary Table 11 - Sensitivity analysis varying the proportions of individuals reached by an alternative strategy at $20 \%$ and $100 \%$ : cost-effectiveness analysis with treatment initiation regardless of fibrosis stage.

Supplementary Table 12 - Sensitivity analysis decreasing the proportions of individuals initiating a treatment following screening to 50\%: cost-effectiveness analysis with treatment initiation regardless of fibrosis stage.

Supplementary Table 13 - Sensitivity analysis varying the probabilities of HCV progression by $\pm 20 \%$ : cost-effectiveness analysis with treatment initiation regardless of fibrosis stage .. 29

Supplementary Table 14 - Sensitivity analysis varying the cost related to health stages by \pm 20\%: cost-effectiveness analysis with treatment initiation regardless of fibrosis stage

Supplementary Table 15 - Sensitivity analysis varying the cost related to screening by $\pm 20 \%$ : cost-effectiveness analysis with treatment initiation regardless of fibrosis stage

Supplementary Table 16 - Sensitivity analysis varying the cost related to treatment initiation and follow-up (out of drugs cost) by $\pm 20 \%$ : cost-effectiveness analysis with treatment initiation regardless of fibrosis stage.

Supplementary Table 17 - Sensitivity analysis varying drugs cost by $\pm 20 \%$ : costeffectiveness analysis with treatment initiation regardless of fibrosis stage.....

Supplementary Table 18 - Sensitivity analysis varying the health-related utilities by $\pm 20 \%$ : cost-effectiveness analysis with treatment initiation regardless of fibrosis stage.....

Supplementary Table 19 - Sensitivity analysis varying the probabilities of SVR by $\pm 5 \%$ : cost-effectiveness analysis with treatment initiation regardless of fibrosis stage.

Supplementary Table 20 - Sensitivity analysis using alternative distribution of the study population [13]: cost-effectiveness analysis with treatment initiation regardless of fibrosis stage. 
Supplementary Table 21 - Sensitivity analysis of results considering costs related to severe anemia leading to transfusion for patients initiating ribavirin [25]: cost-effectiveness analysis with treatment initiation regardless of fibrosis stage

Supplementary Table 22 - Bivariate sensitivity analysis of increasing screening uptake from $50 \%$ to $100 \%$ and cost of screening (Hepatitis C antibody test, HCV-RNA test) from $0 \%$ to 20\%: average lifetime cost per person for the universal strategy and ICER for the universal screening strategy compared to the strategy targeting all individuals 40-80.

Supplementary References ...... 


\section{Model structure}

The testing decision tree was first divided according to the different screening strategies and according to the characteristics of individuals (Supplementary Fig. 1a). Then for each profile of individuals the Markov-based model simulated the progression through disease stages. At each cycle (one year) of the Markov model (Supplementary Fig. 1b), patients either remained at the same disease stage or progressed to a more severe stage. Probability of disease progression was based on international literature (Supplementary Table 1). Chronic hepatitis $\mathrm{C}$ was represented by different METAVIR fibrosis stages [1]. Fibrosis progression varied by sex, age and alcohol abuse [2]. Once patients had compensated cirrhosis (F4), they were at risk of developing liver decompensation according to alcohol abuse [3, 4] and hepatocellular carcinoma (HCC) related to age and sex [5]. Liver decompensation was divided into the following stages: (i) the first year of decompensation following ascites, gastrointestinal bleeding, encephalopathy or icterus; (ii) the period following initial decompensation, either stable or progressive decompensation based on the occurrence (or not) of successive decompensation episodes. Distribution into either progressive or stable decompensation was assumed to be 50\% [6]. Patients in liver decompensation or HCC were considered for liver transplantation and probabilities were estimated from recent modeling studies [7, 8]. Finally, HCV-related mortality was defined as deaths occurring in patients with cirrhosis (F4), liver decompensation, HCC or after transplantation. Probability of HCV-related death from F4 or decompensated cirrhosis was extracted from a systematic review [9]. In F4 patients without complications, the probability of $\mathrm{HCV}$-related death was estimated at $1 \%$ per year. In contrast, the probability of HCV-related death during the first year of decompensated cirrhosis was estimated at 39\%. After the first year, patients had lower risk of HCV-related death:

$12.5 \%$ per year for stable decompensation and $15.6 \%$ per year for progressive decompensation, extracted from cumulative survival rates in patients in Child-Pugh B and C 
stages, respectively [9]. Probability of HCV-related death after HCC was considered to be time-dependent, with a higher death rate during the first year, 54\%, compared to subsequent years, i.e. $27 \%$ [8]. Finally, transition probabilities from liver transplantation to HCV-related death was obtained via the French Agence de Biomédecine [10]. Background mortality probabilities, according to age and sex, were derived from French life tables [11].

\section{Study population}

The study population consisted of the French general population aged 18 to 80 years, without any known diagnosis of HCV-RNA positivity. Characteristics of this population were issued from the 2004 national seroprevalence survey of the French National Public Health agency $[12,13]$. This cross-sectional survey among a random sample of residents of mainland France was conducted in 2004 to estimate the prevalence of hepatitis B and C virus infections. Selected individuals received an invitation letter for a free medical checkup. An anti-HCV antibody screening test was first carried out for all participants. HCV RNA detection was then performed for those individuals diagnosed anti-HCV positive. Data were collected for demographic characteristics, potential exposure to $\mathrm{HCV}$ and any prior HCV screening and results. Awareness of $\mathrm{HCV}$ infection was assessed using these two last variables. This study used a complex sampling design to attempt to control as much as possible for selection bias. In particular, it included high-risk population for $\mathrm{HCV}$ : among the 14,416 adult participants enrolled, $0.64 \%$ were intravenous drug users, $2.6 \%$ were nasal drug users and $23.5 \%$ were born abroad mainly from intermediate and high endemicity countries for HCV.

First, to assess and characterize the study population, individuals already aware of their HCVRNA positivity were subtracted from the French general population aged 18 to 80 years according to gender and age. We then obtained determined characteristics of this population in high or low risk population according to the presence or absence of risk factors (Table 1 
and Supplementary Table 2) $[12,13]$. We finally obtained the estimated proportion of HCVRNA positivity in this study population (Table 1) [12, 13].

Second, we fixed the proportion of individuals that will be reached by a given strategy according to gender, age and risk factors level. In the risk-based strategy, individuals were assumed to be tested as observed in the 2004 French survey, i.e. between $4 \%$ and $18 \%$ for individuals without risk factors and between $10 \%$ and $19 \%$ for those with risk factors (Table 2). For the new screening strategies, we assumed that $50 \%$ of targeted individuals were tested. For example, in the strategy targeting all men between 18 and 59 years, the proportion of tested men aged 18 to 59 was $50 \%$, regardless of risk factors (Table 2).

Third, because excessive alcohol abuse was recognized as a risk factor of CHC progression $[2,4]$, we obtained the distribution of excessive alcohol abuse by gender and age using a previously published model [7], i.e. in males: $26 \%$ in $18-39,18 \%$ in $40-59$ and $3 \%$ in $60-80$; in females: $6 \%, 4 \%$ and $2 \%$, respectively.

Finally, the study population was stratified into fibrosis stage according to our previous modeling [7] (Supplementary Table 3). The estimated repartitions in fibrosis stage by gender, age and alcohol status of undiagnosed individuals were applied for individuals unreached by a given screening strategy at the beginning of the simulations, whereas those of diagnosed untreated individuals were applied for individuals that will be reached by the evaluated strategy [7]. For individuals unreached by a given strategy, we set a mean time until diagnosis according to gender, age and alcohol status. These mean times were calculated from the two distributions of fibrosis (diagnosed and undiagnosed individuals) by multiplying the difference of average fibrosis stage among diagnosed and undiagnosed individuals by the inverse of fibrosis transition rate, according to gender, age and alcohol status. Undiagnosed patients in decompensated cirrhosis were assumed to be diagnosed in the year of the 1 st 
decompensation whatever the strategy. These average times were included in the modeling for individuals unreached by a strategy. Globally, they corresponded to 1.95 years with the current risk-based strategy compared to 1.53 year when adding the screening of all men between 18 and 59 years, 1.82 when adding the screening of all individuals between 40 and 59 years, 1.73 years when adding the screening of all individuals between 40 and 80 years, and 1.18 years with universal screening.

\section{Cost data}

Cost inputs were limited to direct medical costs associated with HCV screening, HCV care and HCV treatment. Costs of HCV screening included the test for HCV antibodies, and when positive, a second $\mathrm{HCV}$-antibodies test with HCV-RNA screening test to confirm chronic hepatitis C.

To estimate resource consumption for $\mathrm{HCV}$ care, we focused on ambulatory and acute hospital care of HCV mono-infected patients (Supplementary Table 4). To estimate resources used during ambulatory care, we conducted a retrospective survey of 128 consecutive patients who consulted their physician in 2011 (follow-up, 2.4 person-years) at a HCV care reference center (i.e. Assistance Publique, Hôpitaux de Paris, Cochin Hospital, Paris, France). To estimate resources used during inpatient stay, we also used the 2008-2010 French national database in which we identified 49,391 patients who were tracked over 3 years. Resources used were estimated for both ambulatory and acute hospital, but only concerning patients who were not on antiviral treatment and who were stratified by disease stage (F0-2, F3, F4, decompensated cirrhosis, HCC and liver transplant). To estimate costs, we assigned unit costs to each resource used and attributable to liver disease care. Regarding ambulatory costs, we relied on public tariffs of specialist visits, laboratory tests [14] and clinical procedures [15]. Regarding hospital costs, we used the French diagnosis-related group (DRG) classification 
system [16]. The DRG system classifies diseases into medically and economically homogenous groups. DRG costs include physicians' and nurses' fees as well as mean cost of diagnosis, clinical procedures, laboratory tests, drugs dispensed during hospitalization and hotel/overhead costs.

We also estimated health care use for monitoring HCV treatments using French treatment guidelines (i.e. outpatient visits, laboratory tests, HCV-RNA tests, liver function tests).

Regarding costs related to adverse events, severe anemia necessitating transfusion for patients initiating ribavirin was only considered in sensitivity analysis (see below).

\section{Health-related quality of life}

A cross-sectional study was conducted in three French referral hepatology centers (Paris, Lille in northern France, and Montpellier in southern France) [17]. Patients included were aged 1870, $\mathrm{CHC}$ mono-infected, treatment-naives, relapsers (having received up to 2 treatments in the past), or non-responders, and were enrolled before treatment initiation. By January 2015, 505 patients were enrolled. Health utilities were estimated using EuroQol-5D and French TimeTrade-Off value set for patients in stage of fibrosis F0 to F4 (Supplementary Table 5) [18]. Number of patients in decompensated cirrhosis and HCC was too small to evaluate health utilities in complicated stages. Health utilities were therefore estimated from our estimate obtained for stage F4 and assuming the same decrease between patients in F4 and those in complicated stages observed in another study implemented in France, UK and Germany (Adelphi study) [19]. We assumed no loss in health utilities from being identified as HCVpositive or under treatment with IFN-free regimens. 


\section{Sensitivity analysis}

Firstly, we performed a one-way deterministic sensitivity analysis, varying values of input parameters that may change our conclusions by $\pm 20 \%$. In particular, we varied the proportions of high-risk population, HCV-RNA positivity, excessive alcohol consumption and individuals reached by the current screening strategy; the probabilities of HCV progression; the cost related to health stages, screening tests and treatment follow-up; drug cost; and the health-related utilities as well as post-SVR utility gains. Moreover, we varied the proportion of individuals that will be reached by a new strategy on the interval $20-100 \%$, the proportion of the targeted population that will be treated on the interval $50-100 \%$, and we varied the probability of SVR by $\pm 5 \%$.

Regarding costs related to adverse events, severe anemia necessitating transfusion for patients initiating ribavirin was considered for a cost of $2,564 €$; this was estimated to happen for $0.3 \%$ of these patients $(2.7 \%$ having severe anemia among which $10 \%$ would necessitate a transfusion) [20].

Secondly, a two-way deterministic sensitivity analysis for universal screening was conducted by increasing simultaneously uptake from $50 \%$ to $100 \%$ and cost of screening tests from $0 \%$ to $20 \%$.

Finally, a probability sensitivity analysis was performed to account for uncertainty by simultaneously varying all input parameters from appropriate probability distributions (Supplementary Table 6). $\alpha$ and $\beta$ parameters of Beta and Gamma distribution were derived from the average values $E(x)$ and standard errors $\sigma$-if known, $20 \%$ of the average otherwise - using the following equations:

Beta:

$$
\alpha=\frac{E(x)^{2} /(1-E(x))}{\sigma^{2}}-E(x) \quad \beta=\frac{\alpha(1-E(x))}{E(x)}
$$


Gamma:

$$
\alpha=\frac{E(x)^{2}}{\sigma^{2}}
$$

$$
\beta=\frac{E(x)}{\sigma^{2}}
$$


Figure S1. Model structure: a) Testing decision tree; b) Markov-based model of chronic hepatitis $\mathrm{C}$ progression. $\mathrm{OH}$ - corresponds to no alcohol abuse (0-50g/day), $\mathrm{OH}+$ corresponds to alcohol abuse $(>50 \mathrm{~g} / \mathrm{day})$

a)

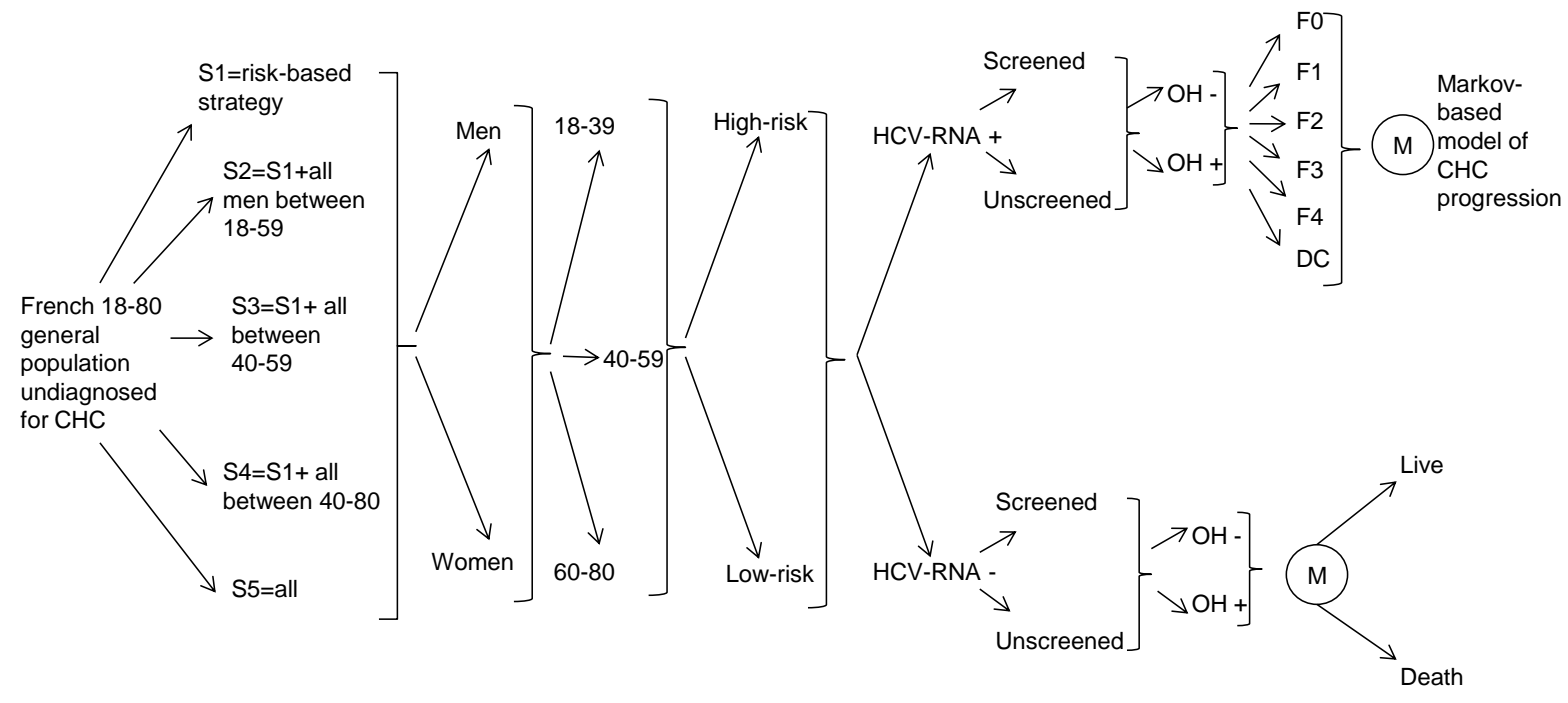

b)

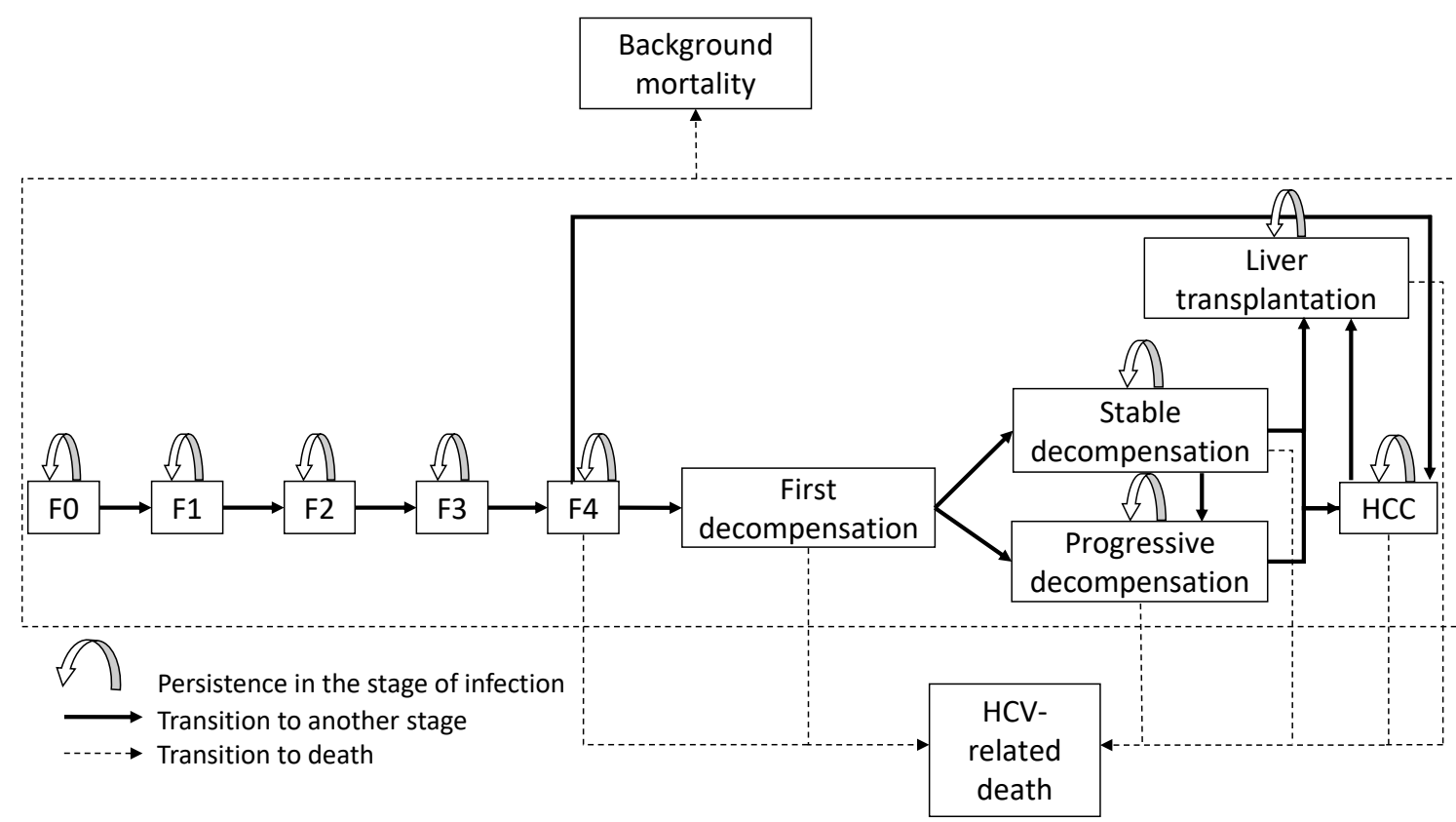


Figure S2. Predicted cumulative incidence of cirrhosis (F4), decompensated cirrhosis, hepatocellular carcinoma and liver deaths among CHC population after 10 years (A) and 20 years (B): base case analysis. 


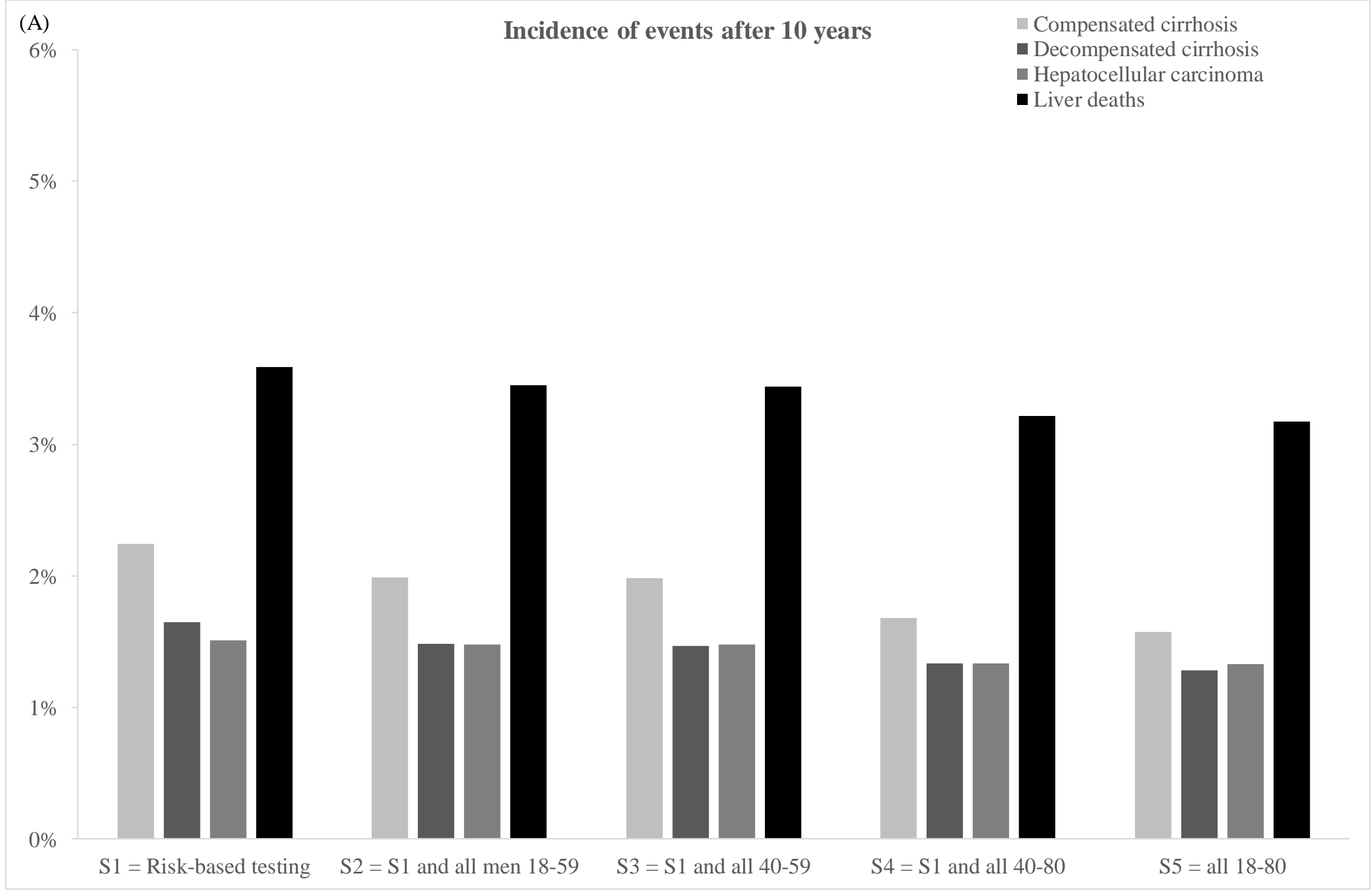


(B)

$6 \%$

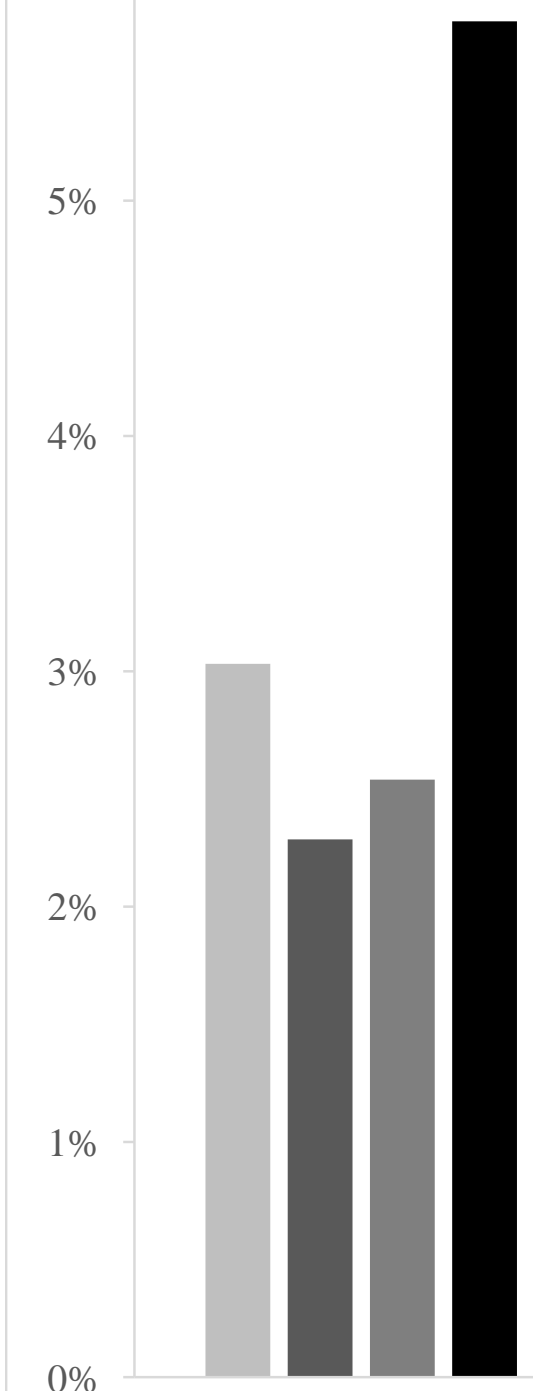

$\mathrm{S} 1$ = Risk-based testing
Incidence of events after 20 years

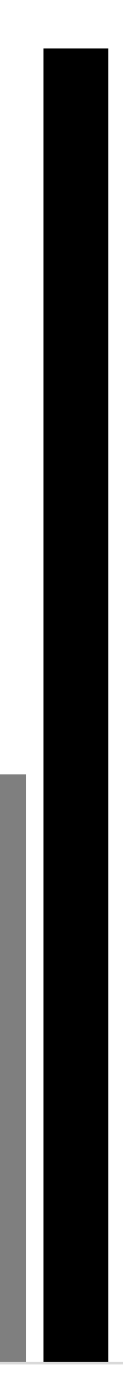

S2 = S1 and all men 18-59

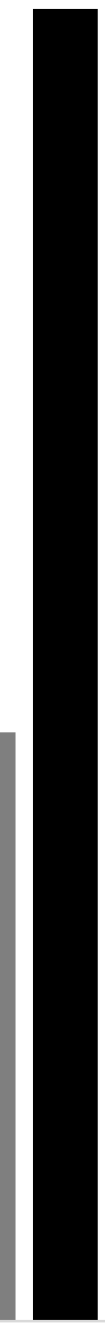

$\mathrm{S} 3=\mathrm{S} 1$ and all 40-59
- Compensated cirrhosis

- Decompensated cirrhosis

- Hepatocellular carcinoma

- Liver deaths

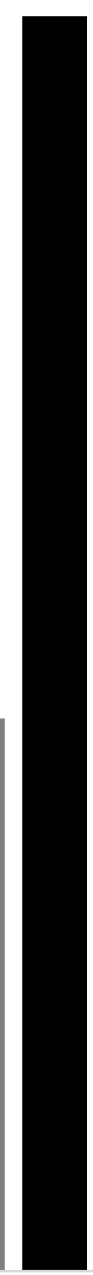

$\mathrm{S} 4=\mathrm{S} 1$ and all 40-80

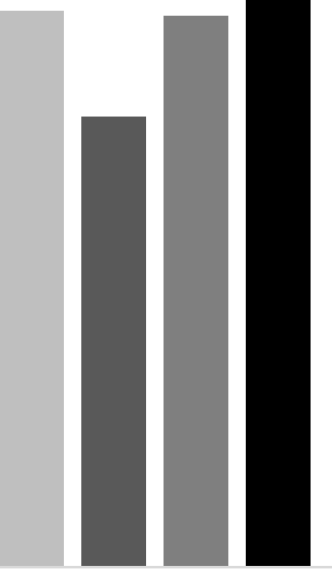

S5 = all 18-80 
Supplementary Table 1 - Parameters of progression of chronic hepatitis $\mathrm{C}$ (CHC) and impact of treatment on progression

\begin{tabular}{|c|c|c|}
\hline Parameters & Value & References \\
\hline Natural history of CHC & Probability (range) & \\
\hline Fibrosis transition in women, alcohol-negative ${ }^{*}$ & & {$[2,7]$} \\
\hline $0-40$ & $0.049(0.045-0.053)$ & \\
\hline $41-50$ & $0.052(0.046-0.058)$ & \\
\hline $51-60$ & $0.055(0.051-0.058)$ & \\
\hline $61-70$ & $0.089(0.087-0.091)$ & \\
\hline$>70$ & $0.077(0.076-0.078)$ & \\
\hline Fibrosis transition in men, alcohol-negative* & & {$[2,7]$} \\
\hline $0-40$ & $0.035(0.034-0.036)$ & \\
\hline $41-50$ & $0.094(0.092-0.096)$ & \\
\hline $51-60$ & $0.141(0.139-0.143)$ & \\
\hline $61-70$ & $0.244(0.240-0.247)$ & \\
\hline$>70$ & $0.193(0.185-0.202)$ & \\
\hline \multicolumn{3}{|l|}{ Transition from F4 (compensated cirrhosis) to: } \\
\hline First decompensation (alcohol-negative) ${ }^{*}$ & 0.05 & [3] \\
\hline HCC (age- and sex-dependent) & & {$[5]$} \\
\hline Women, according to age $x$ & $0.017 \times 1.05^{(x-57)}$ & \\
\hline Men, according to age $x$ & $0.036 \times 1.05^{(x-57)}$ & \\
\hline HCV-related death & $0.010(0.010-0.034)$ & [9] \\
\hline \multicolumn{3}{|l|}{ Transition from first decompensation to: } \\
\hline Stable or progressive decompensation & $0.50(0.40-0.60)$ & {$[6]$} \\
\hline HCV-related death & $0.39(0.20-0.55)$ & [9] \\
\hline \multicolumn{3}{|l|}{ Transition from stable decompensation to: } \\
\hline $\mathrm{HCC}$ & Same as F4 & Assumption \\
\hline LT (age $\leq 70)$ & 0.120 & {$[7,21]$} \\
\hline HCV-related death & 0.125 & [9] \\
\hline \multicolumn{3}{|l|}{ Transition from progressive decompensation to: } \\
\hline $\mathrm{HCC}$ & Same as F4 & Assumption \\
\hline LT $($ age $\leq 70)$ & 0.120 & {$[7,21]$} \\
\hline HCV-related death & 0.156 & [9] \\
\hline
\end{tabular}


Supplementary Table 1 - (continued)

\begin{tabular}{lrr}
\hline Parameters & Value & References \\
\hline Transition from HCC to: & Probability (range) & \\
LT (age 70) & 0.170 & {$[7,21]$} \\
HCV-related death (time-dependent) & & {$[21]$} \\
First year after onset of HCC & 0.54 & \\
Following years after HCC onset & 0.27 & \\
Transition from LT to HCV-related death & & \\
First year after LT & 0.160 & \\
Following years after LT & 0.032 & \\
Patients achieving SVR at F4 stage ${ }^{\dagger}$ & RR (range) \\
HCV-related death & $0.06(0.02-0.19)$ \\
Liver decompensation & $0.07(0.03-0.20)$ & \\
HCC development & $0.19(0.08-0.44)$ & \\
\hline
\end{tabular}

CHC, chronic hepatitis C; HCC, hepatocellular carcinoma; LT, liver transplantation.

${ }^{*}$ Fibrosis transition rates in alcohol-positive patients were 3 times higher at F0, F1, F2 and F3, and 4.5 times higher at F4 [4]; ' Relative risk of liver progression or death in patients who achieved SVR at F4 stage versus treatment failure or no treatment. 
Supplementary Table 2 - French recommendations for HCV screening based on risk

\section{factors $[12,23]$}

Persons who have received blood products or tissue transplant, cells or organs, before 1992;

Persons who injected drugs at least once in their lives;

Persons having undergone endoscopic examinations with biopsy;

Persons having had invasive radiological exams;

Persons being hemophilic;

Persons undergoing haemodialysis;

Prisoners and previously incarcerated persons;

Persons from or who received care in countries with a high HCV endemicity (Southeast Asia, Middle East, Africa, South America)

Persons who have had tattoos, body piercing, sclerosis varices, acupuncture or mesotherapy procedures 
Supplementary Table 3 - Disease stage distribution according to gender, age and alcohol status, and average time until diagnosis [7]

\begin{tabular}{|c|c|c|c|c|c|c|c|c|c|c|c|c|}
\hline & \multicolumn{6}{|c|}{ Males } & \multicolumn{6}{|c|}{ Females } \\
\hline & \multicolumn{3}{|c|}{ Alcohol (0-50g/day) } & \multicolumn{3}{|c|}{ Alcohol (>50g/day) } & \multicolumn{3}{|c|}{ Alcohol (0-50g/day) } & \multicolumn{3}{|c|}{ Alcohol (>50g/day) } \\
\hline & $18-39$ & $40-59$ & $60-80$ & $18-39$ & $40-59$ & $60-80$ & $18-39$ & $40-59$ & $60-80$ & $18-39$ & $40-59$ & $60-80$ \\
\hline \multicolumn{13}{|c|}{ Disease stage distribution for undiagnosed individuals, $\%$} \\
\hline Fibrosis F0 & 66.0 & 21.9 & 2.4 & 41.5 & 6.3 & 2.5 & 58.7 & 27.7 & 13.2 & 32.9 & 9.5 & 3.0 \\
\hline Fibrosis F1 & 24.7 & 29.9 & 7.8 & 30.7 & 13.6 & 3.3 & 27.9 & 33.3 & 25.9 & 29.0 & 16.3 & 8.7 \\
\hline Fibrosis F2 & 6.9 & 24.4 & 15.3 & 17.6 & 20.6 & 5.4 & 9.9 & 23.3 & 27.5 & 20.7 & 24.8 & 18.8 \\
\hline Fibrosis F3 & 1.5 & 14.8 & 21.6 & 6.8 & 17.7 & 6.6 & 2.8 & 11.3 & 20.5 & 10.0 & 20.7 & 19.8 \\
\hline Fibrosis F4 & 0.8 & 8.6 & 50.4 & 2.9 & 34.5 & 65.2 & 0.7 & 4.1 & 12.4 & 6.3 & 23.6 & 40.6 \\
\hline Decompensated cirrhosis, $1^{\text {st }}$ year & 0.0 & 0.4 & 2.6 & 0.5 & 7.3 & 17.0 & 0.0 & 0.2 & 0.6 & 1.2 & 5.1 & 9.2 \\
\hline Decompensated cirrhosis, $>1$ years & 0.0 & 0.0 & 0.0 & 0.0 & 0.0 & 0.0 & 0.0 & 0.0 & 0.0 & 0.0 & 0.0 & 0.0 \\
\hline \multicolumn{13}{|c|}{ Disease stage distribution for diagnosed individuals, $\%$} \\
\hline Fibrosis F0 & 55.7 & 22.7 & 1.8 & 32.0 & 2.7 & 0.0 & 48.5 & 28.4 & 14.0 & 21.0 & 3.1 & 0.6 \\
\hline Fibrosis F1 & 31.2 & 33.4 & 7.0 & 32.7 & 7.2 & 0.1 & 34.7 & 38.8 & 29.9 & 26.5 & 8.9 & 2.8 \\
\hline Fibrosis F2 & 8.0 & 22.4 & 11.7 & 18.6 & 9.8 & 0.2 & 11.8 & 19.9 & 25.5 & 18.8 & 12.1 & 5.7 \\
\hline
\end{tabular}




\begin{tabular}{|c|c|c|c|c|c|c|c|c|c|c|c|c|}
\hline Fibrosis F3 & 1.6 & 11.6 & 14.8 & 7.2 & 7.9 & 0.3 & 3.2 & 7.9 & 16.2 & 9.9 & 9.2 & 5.7 \\
\hline Fibrosis F4 & 0.6 & 6.0 & 33.3 & 3.0 & 14.5 & 3.1 & 0.8 & 2.7 & 8.8 & 6.4 & 10.9 & 10.7 \\
\hline Decompensated cirrhosis, $1^{\text {st }}$ year & 0.0 & 0.3 & 1.7 & 0.6 & 3.1 & 0.8 & 0.0 & 0.1 & 0.4 & 1.2 & 2.4 & 2.4 \\
\hline Decompensated cirrhosis, $>1$ years & 2.8 & 3.7 & 29.6 & 5.9 & 54.8 & 95.5 & 0.9 & 2.1 & 5.2 & 15.2 & 53.5 & 72.2 \\
\hline \multicolumn{13}{|l|}{ Average time until diagnosis, years ${ }^{*}$} \\
\hline Patients in F0-2 & 6 & 1 & 1 & 3 & 2 & 1 & 3 & 1 & 1 & 4 & 6 & 3 \\
\hline Patients in F3-4 & 6 & 1 & 1 & 2 & 2 & 1 & 3 & 1 & 1 & 3 & 4 & 2 \\
\hline
\end{tabular}

"Undiagnosed patients in decompensated cirrhosis were assumed to be diagnosed in the year of the $1^{\text {st }}$ decompensation 
Supplementary Table 4 - Annual costs (standard deviation) attributable to chronic hepatitis C: ambulatory costs (never-treated and after HCV treatment failure) and hospitalization costs (no death and in-hospital death) [24]

\begin{tabular}{lcccc}
\hline Liver disease stage & \multicolumn{2}{c}{ Ambulatory costs, mean (SD) $€$} & \multicolumn{2}{c}{ Hospitalization costs, mean (SD) $€$} \\
& Never-treated & After treatment failure & No death & In-hospital death \\
\hline Fibrosis F0 to F2 & $70(10)$ & $53(12)$ & $278(1,087)$ & $337(1,377)$ \\
Fibrosis F3 & $128(22)$ & $86(15)$ & & $6,450(11,422)$ \\
Cirrhosis, compensated (F4) & $228(20)$ & $71(18)$ & & $1,295(3,732)$ \\
Cirrhosis, decompensated & & & & $1,059(11,226)$ \\
First year or stable & $96(21)$ & $96(21)$ & $15,032(17,552)$ & $19,935(20,639)$ \\
Progressive & $96(21)$ & $96(21)$ & $11,745(11,634)$ & $16,643(14,137)$ \\
HCC & $96(21)$ & $96(21)$ & & $90,712(55,462)$ \\
Liver transplant & & 0 & $56,021(40,329)$ & $15,911(23,307)$ \\
First year & 0 & 0 & $5,445(11,123)$ & \\
\hline Following years & 0 & & & \\
\hline
\end{tabular}




\section{Supplementary Table 5 - Health-related utilities}

Value References

Health-related utilities in $\mathrm{CHC}$ patients

Fibrosis F0 to F2

0.82

Fibrosis F3 to F4

0.76

Decompensated cirrhosis / Hepatocellular carcinoma

0.60

$[17,19]$

Liver transplant $-1^{\text {st }}$ year

0.55

$[17,19]$

Liver transplant - subsequent year

0.82

$[17,19]$

Health-related utilities in patients after sustained virological response

Sustained virological response from F0-F1

0.95

Sustained virological response from F2-F3-F4

0.85 
Supplementary Table 6 - Distribution used for each model input during probabilistic sensitivity analysis

\begin{tabular}{ll}
\hline Input & Distribution \\
\hline Proportions of high-risk population by gender and age & Beta \\
Proportions of HCV-RNA positivity by gender, age and risk factor & Beta \\
Proportions of excessive alcohol consumption by gender and age & Beta \\
Probabilities of HCV progression by stage and cofactor & Normal \\
Proportions of individuals reached by the current screening strategy by risk factor & Beta \\
Proportions of individuals reached by an alternative screening strategy & Uniform \\
Proportions of treatment initiation & Uniform \\
Proportions of SVR in stage F0-4 and in decompensated cirrhosis & Beta \\
Ambulatory costs related to health stages & Gamma \\
Hospitalization costs related to health stages F0-3 & Triangular \\
Hospitalization costs related to health stages $\geq$ F4 & Log-normal \\
Costs related to screening & Triangular \\
Costs related to treatment (out of drug cost) & Triangular \\
Health-related utilities & Beta \\
Post-SVR utility gains & Uniform \\
\hline
\end{tabular}


Supplementary Table 7 - Sensitivity analysis varying the proportions of high-risk population by $\pm 20 \%$ : cost-effectiveness analysis with treatment initiation regardless of fibrosis stage

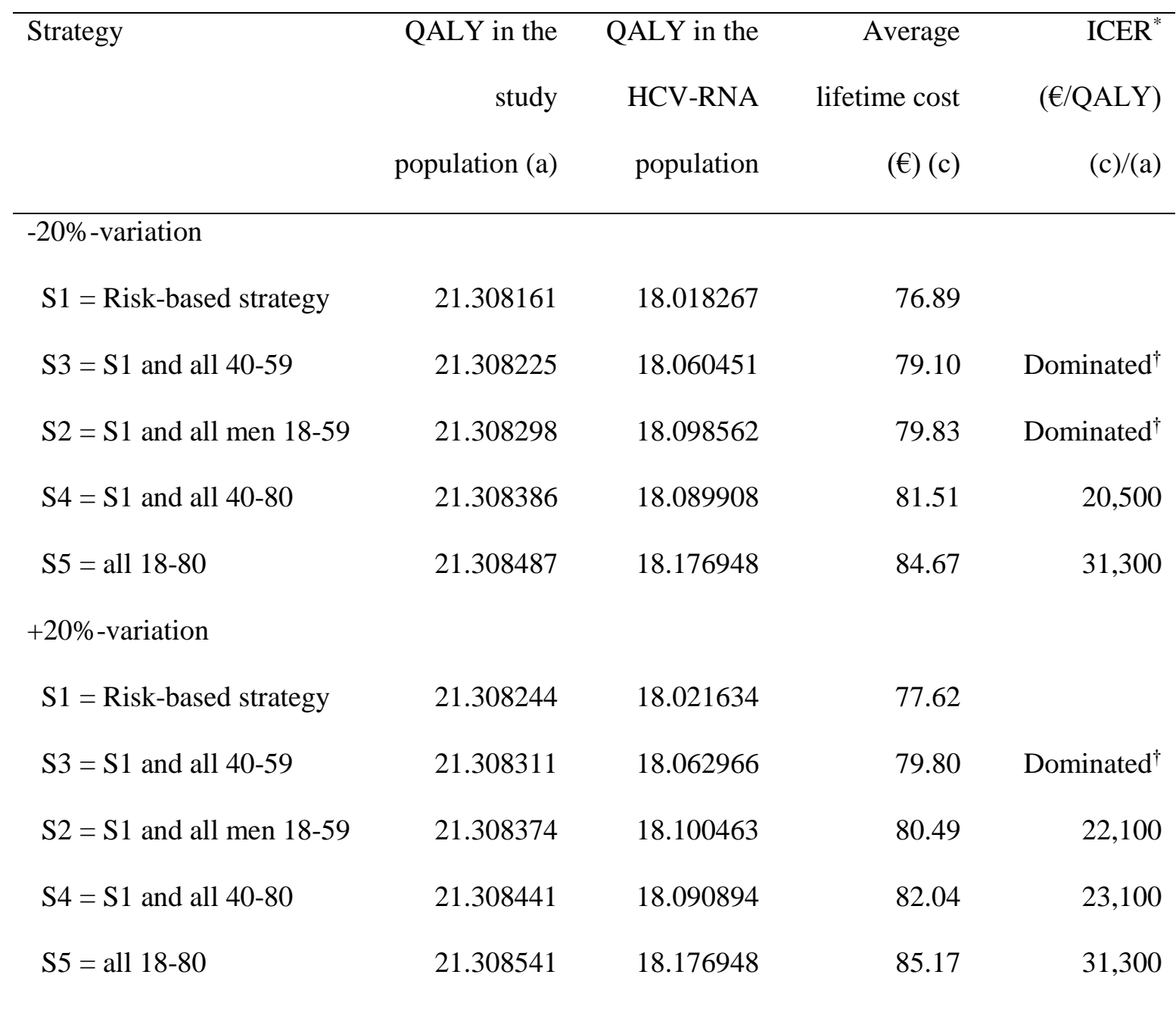

"The comparator for each ICER is the previous least costly strategy; ${ }^{*}$ Weakly dominated strategy: higher ICER than that of a more effective alternative strategy. 
Supplementary Table 8 - Sensitivity analysis varying the proportions of HCV-RNA positivity by $\pm 20 \%$ : cost-effectiveness analysis with treatment initiation regardless of fibrosis stage

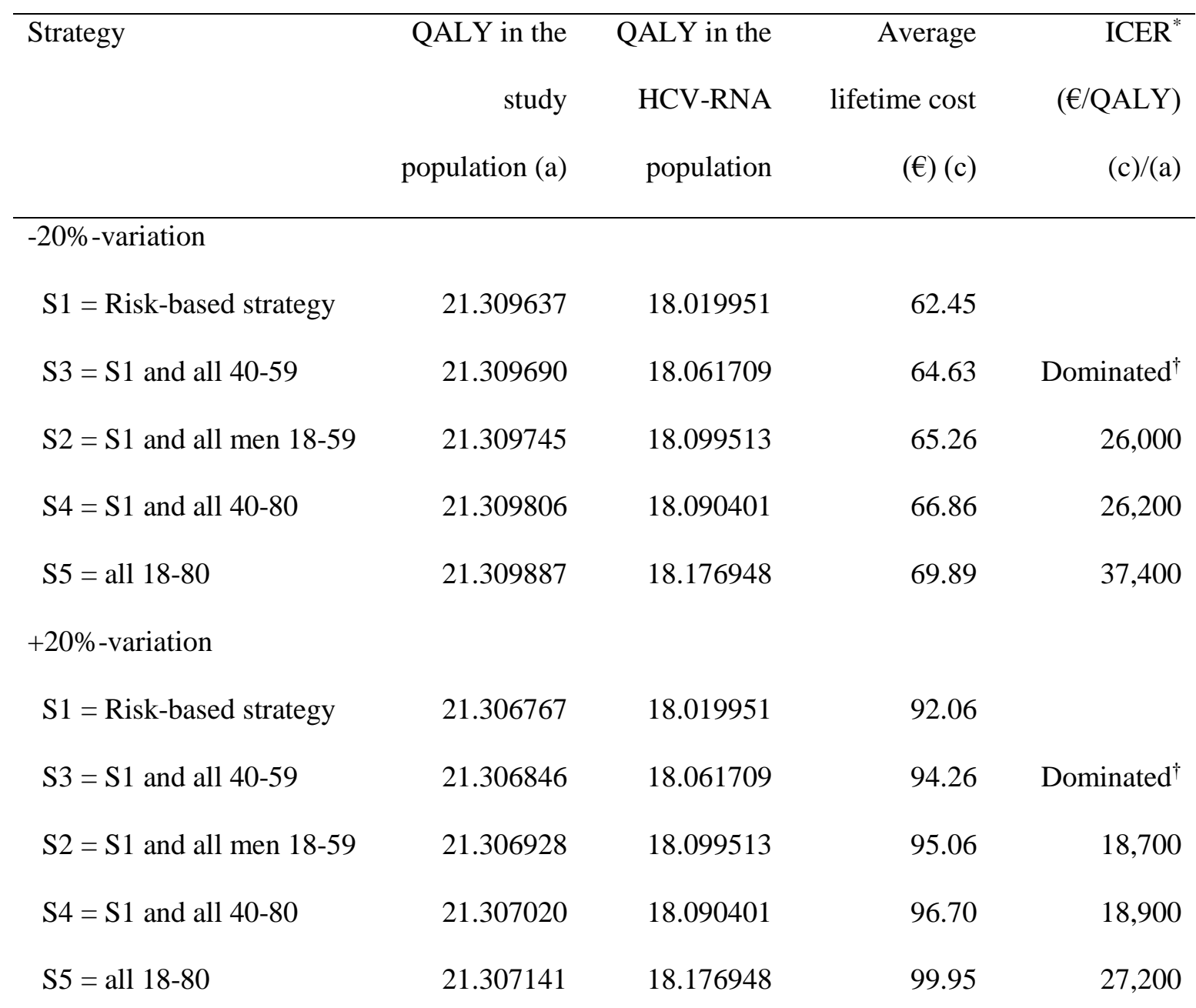

"The comparator for each ICER is the previous least costly strategy; "Weakly dominated strategy: higher ICER than that of a more effective alternative strategy. 
Supplementary Table 9 - Sensitivity analysis varying the proportions of excessive alcohol consumption by $\pm 20 \%$ : cost-effectiveness analysis with treatment initiation regardless of fibrosis stage

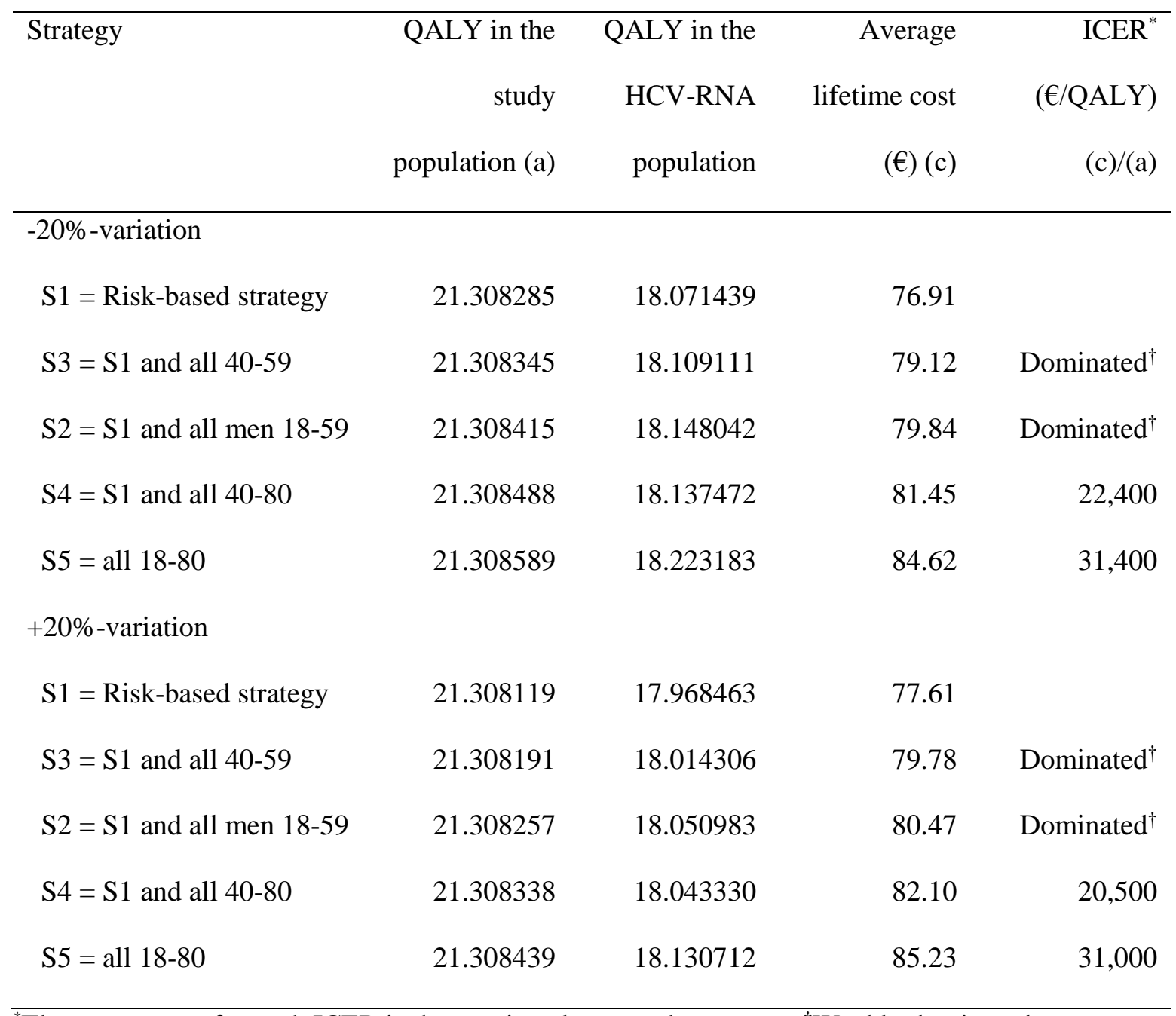

"The comparator for each ICER is the previous least costly strategy; ${ }^{\dagger}$ Weakly dominated strategy: higher ICER than that of a more effective alternative strategy. 
Supplementary Table 10 - Sensitivity analysis varying the proportions of individuals reached by the current strategy by $\pm 20 \%$ : cost-effectiveness analysis with treatment initiation regardless of fibrosis stage

\begin{tabular}{|c|c|c|c|c|}
\hline Strategy & $\begin{array}{l}\text { QALY in the } \\
\text { study } \\
\text { population (a) }\end{array}$ & $\begin{array}{l}\text { QALY in the } \\
\text { HCV-RNA } \\
\text { population }\end{array}$ & $\begin{array}{r}\text { Average } \\
\text { lifetime cost } \\
(€)(\mathrm{c})\end{array}$ & $\begin{array}{r}\text { ICER }^{*} \\
(€ / Q A L Y) \\
(\mathrm{c}) /(a)\end{array}$ \\
\hline \multicolumn{5}{|l|}{$-20 \%$-variation } \\
\hline $\mathrm{S} 1=$ Risk-based strategy & 21.308176 & 18.004083 & 76.52 & \\
\hline $\mathrm{S} 3=\mathrm{S} 1$ and all $40-59$ & 21.308249 & 18.050666 & 78.96 & Dominated $^{\dagger}$ \\
\hline $\mathrm{S} 2=\mathrm{S} 1$ and all men $18-59$ & 21.308324 & 18.092210 & 79.73 & Dominated $^{\dagger}$ \\
\hline $\mathrm{S} 4=\mathrm{S} 1$ and all $40-80$ & 21.308403 & 18.080886 & 81.43 & 21,600 \\
\hline $\mathrm{S} 5=$ all $18-80$ & 21.308514 & 18.176948 & 84.92 & 31,400 \\
\hline \multicolumn{5}{|l|}{$+20 \%$-variation } \\
\hline S1 = Risk-based strategy & 21.308228 & 18.035819 & 78.00 & \\
\hline $\mathrm{S} 3=\mathrm{S} 1$ and all 40-59 & 21.308287 & 18.072751 & 79.93 & Dominated $^{\dagger}$ \\
\hline $\mathrm{S} 2=\mathrm{S} 1$ and all men $18-59$ & 21.308348 & 18.106815 & 80.59 & Dominated $^{\dagger}$ \\
\hline $\mathrm{S} 4=\mathrm{S} 1$ and all $40-80$ & 21.308424 & 18.099916 & 82.12 & 21,000 \\
\hline $\mathrm{S} 5=$ all $18-80$ & 21.308514 & 18.176948 & 84.92 & 31,100 \\
\hline
\end{tabular}

"The comparator for each ICER is the previous least costly strategy; ${ }^{\dagger}$ Weakly dominated strategy: higher ICER than that of a more effective alternative strategy. 
Supplementary Table 11 - Sensitivity analysis varying the proportions of individuals reached by an alternative strategy at $20 \%$ and $100 \%$ : cost-effectiveness analysis with treatment initiation regardless of fibrosis stage

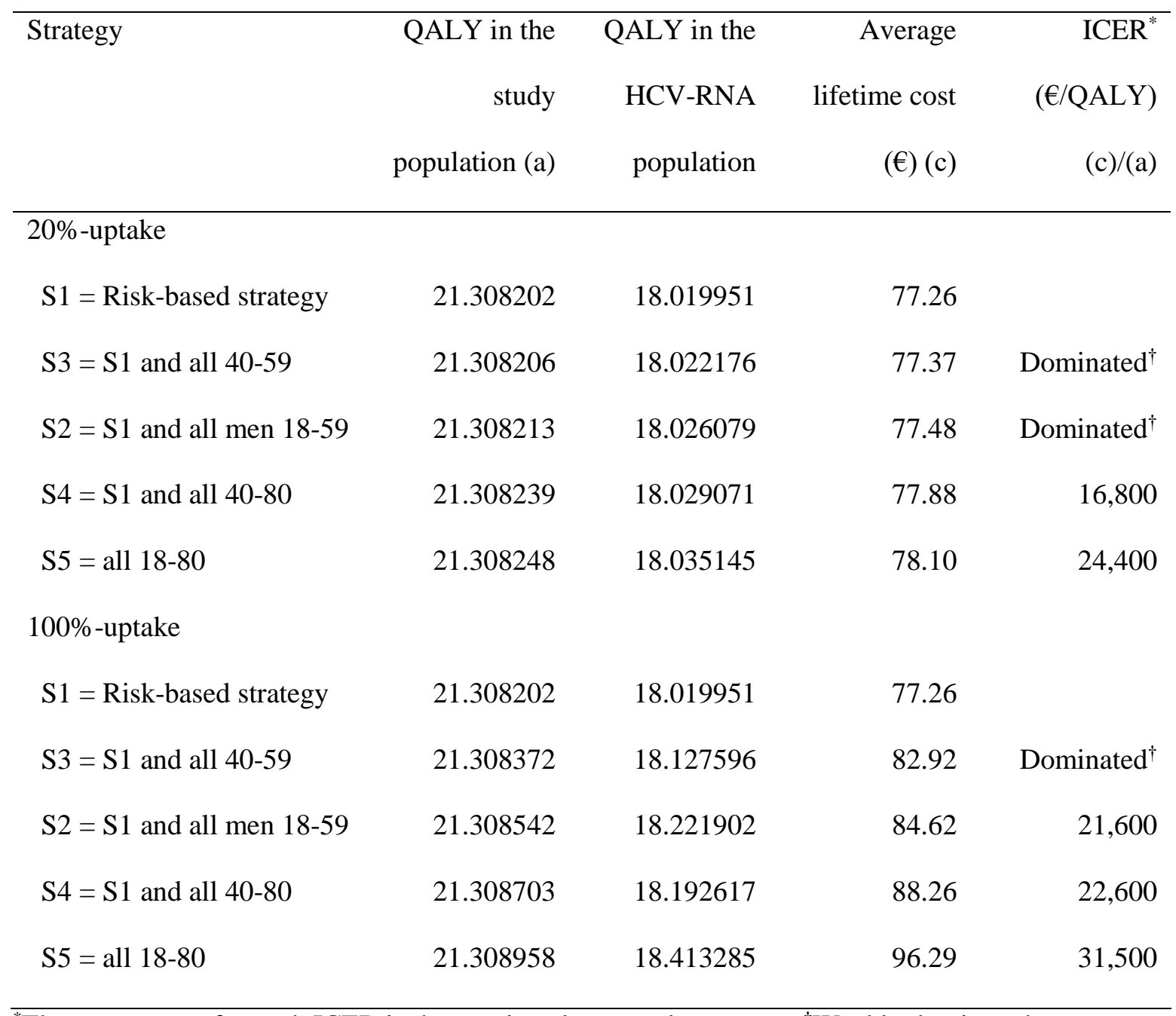

"The comparator for each ICER is the previous least costly strategy; ${ }^{\dagger}$ Weakly dominated strategy: higher ICER than that of a more effective alternative strategy. 
Supplementary Table 12 - Sensitivity analysis decreasing the proportions of individuals initiating a treatment following screening to 50\%: cost-effectiveness analysis with treatment initiation regardless of fibrosis stage

\begin{tabular}{|c|c|c|c|c|}
\hline Strategy & $\begin{array}{r}\text { QALY in the } \\
\text { study }\end{array}$ & $\begin{array}{l}\text { QALY in the } \\
\text { HCV-RNA }\end{array}$ & $\begin{array}{r}\text { Average } \\
\text { lifetime cost }\end{array}$ & $\begin{array}{r}\text { ICER } \\
(€ / \mathrm{OALY})\end{array}$ \\
\hline & population (a) & population & $(€)(\mathrm{c})$ & $(\mathrm{c}) /(\mathrm{a})$ \\
\hline S1 = Risk-based strategy & 21.307708 & 17.806934 & 74.67 & \\
\hline $\mathrm{S} 3=\mathrm{S} 1$ and all $40-59$ & 21.307772 & 17.847581 & 76.88 & Dominated $^{\dagger}$ \\
\hline $\mathrm{S} 2=\mathrm{S} 1$ and all men $18-59$ & 21.307840 & 17.885055 & 77.56 & 21,900 \\
\hline $\mathrm{S} 4=\mathrm{S} 1$ and all $40-80$ & 21.307901 & 17.872947 & 79.25 & 27,700 \\
\hline $\mathrm{S} 5=$ all $18-80$ & 21.308000 & 17.958111 & 82.38 & 31,600 \\
\hline
\end{tabular}

"The comparator for each ICER is the previous least costly strategy; "Weakly dominated strategy: higher ICER than that of a more effective alternative strategy. 
Supplementary Table 13 - Sensitivity analysis varying the probabilities of HCV progression by $\pm 20 \%$ : cost-effectiveness analysis with treatment initiation regardless of fibrosis stage

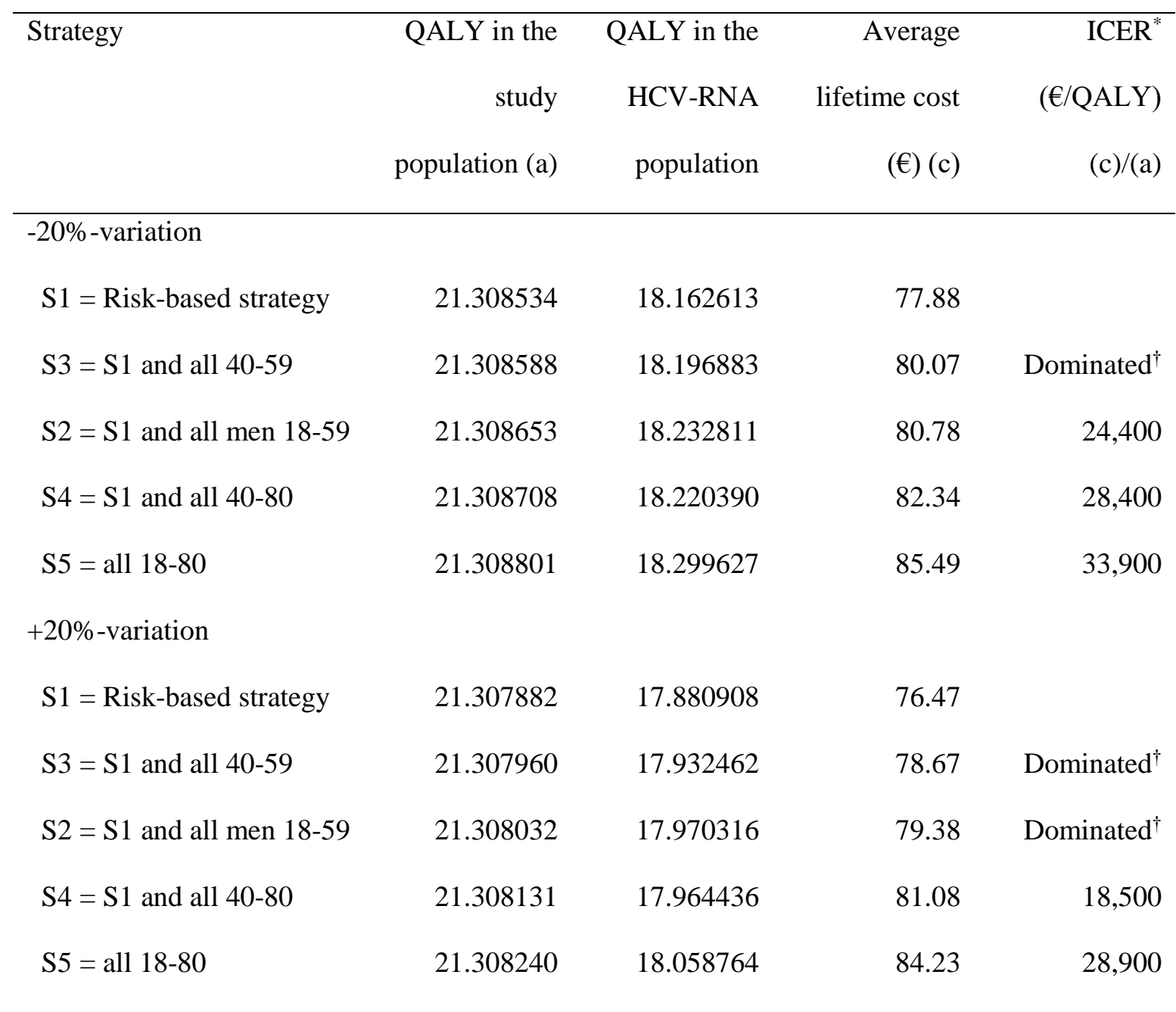

"The comparator for each ICER is the previous least costly strategy; ${ }^{*}$ Weakly dominated strategy: higher ICER than that of a more effective alternative strategy. 
Supplementary Table 14 - Sensitivity analysis varying the cost related to health stages by \pm 20\%: cost-effectiveness analysis with treatment initiation regardless of fibrosis stage

\begin{tabular}{|c|c|c|c|c|}
\hline \multirow[t]{2}{*}{ Strategy } & $\begin{array}{r}\text { QALY in the } \\
\text { study }\end{array}$ & QALY in the & $\begin{array}{r}\text { Average } \\
\text { lifetime }\end{array}$ & $\begin{array}{r}\text { ICER }^{*} \\
(€ / \mathrm{OALY})\end{array}$ \\
\hline & population (a) & population & $(€)(\mathrm{c})$ & (c)/(a) \\
\hline \multicolumn{5}{|l|}{$-20 \%$-variation } \\
\hline $\mathrm{S} 1=$ Risk-based strategy & 21.308202 & 18.019951 & 75.01 & \\
\hline $\mathrm{S} 3=\mathrm{S} 1$ and all 40-59 & 21.308268 & 18.061709 & 77.25 & Dominated $^{\dagger}$ \\
\hline $\mathrm{S} 2=\mathrm{S} 1$ and all men $18-59$ & 21.308336 & 18.099513 & 77.98 & Dominated $^{\dagger}$ \\
\hline $\mathrm{S} 4=\mathrm{S} 1$ and all $40-80$ & 21.308413 & 18.090401 & 79.68 & 22,100 \\
\hline $\mathrm{S} 5=$ all $18-80$ & 21.308514 & 18.176948 & 82.86 & 31,500 \\
\hline \multicolumn{5}{|l|}{$+20 \%$-variation } \\
\hline $\mathrm{S} 1$ = Risk-based strategy & 21.308202 & 18.019951 & 79.51 & \\
\hline $\mathrm{S} 3=\mathrm{S} 1$ and all 40-59 & 21.308268 & 18.061709 & 81.65 & Dominated $^{\dagger}$ \\
\hline $\mathrm{S} 2=\mathrm{S} 1$ and all men $18-59$ & 21.308336 & 18.099513 & 82.34 & Dominated $^{\dagger}$ \\
\hline $\mathrm{S} 4=\mathrm{S} 1$ and all $40-80$ & 21.308413 & 18.090401 & 83.87 & 20,700 \\
\hline $\mathrm{S} 5=$ all $18-80$ & 21.308514 & 18.176948 & 86.98 & 30,800 \\
\hline
\end{tabular}

"The comparator for each ICER is the previous least costly strategy; "Weakly dominated strategy: higher ICER than that of a more effective alternative strategy. 
Supplementary Table 15 - Sensitivity analysis varying the cost related to screening by $\pm 20 \%$ (Hepatitis C antibody test, HCV-RNA test): cost-effectiveness analysis with treatment initiation regardless of fibrosis stage

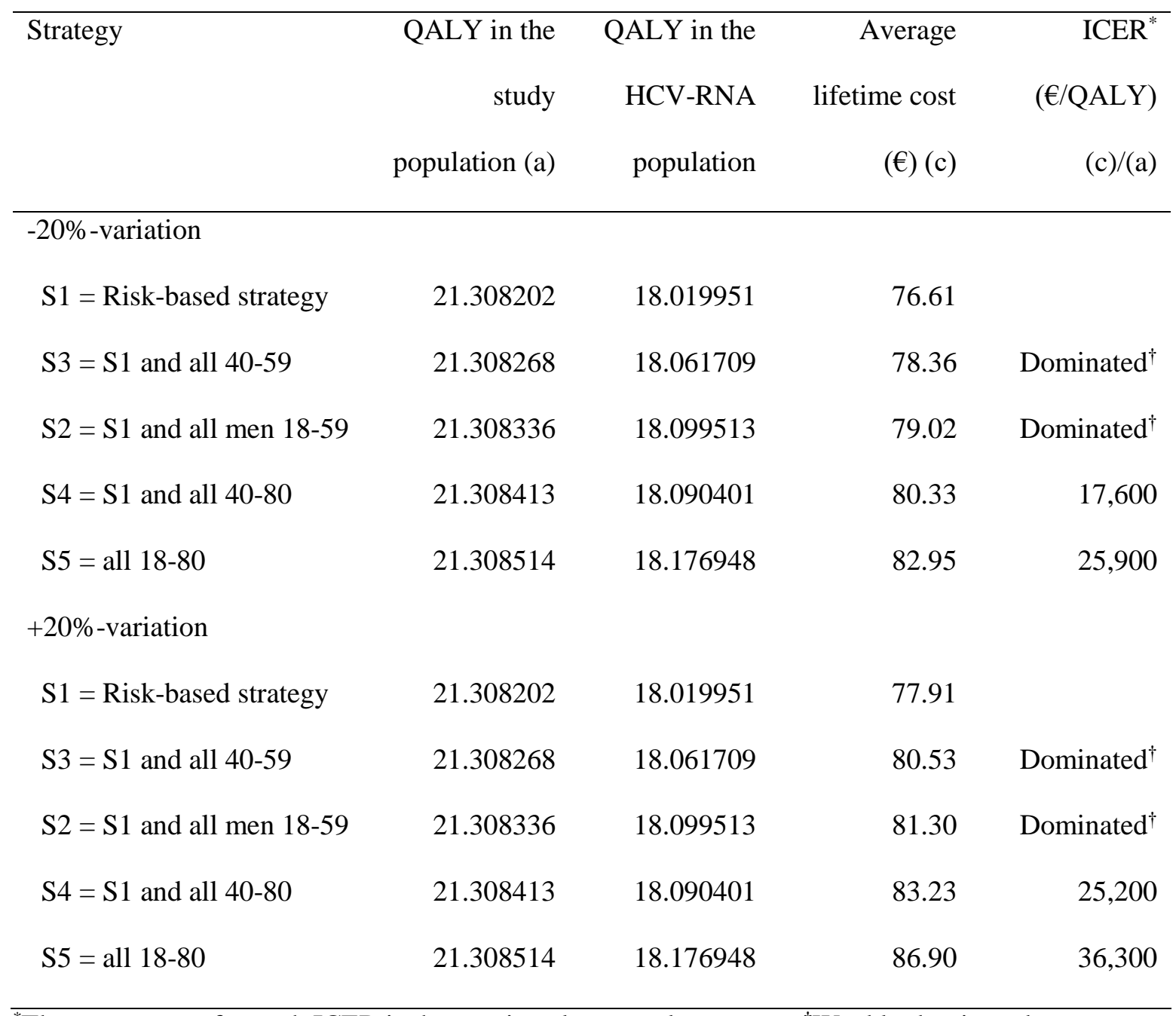

"The comparator for each ICER is the previous least costly strategy; ${ }^{\dagger}$ Weakly dominated strategy: higher ICER than that of a more effective alternative strategy. 
Supplementary Table 16 - Sensitivity analysis varying the cost related to treatment initiation and follow-up (out of drugs cost) by $\pm 20 \%$ : cost-effectiveness analysis with treatment initiation regardless of fibrosis stage

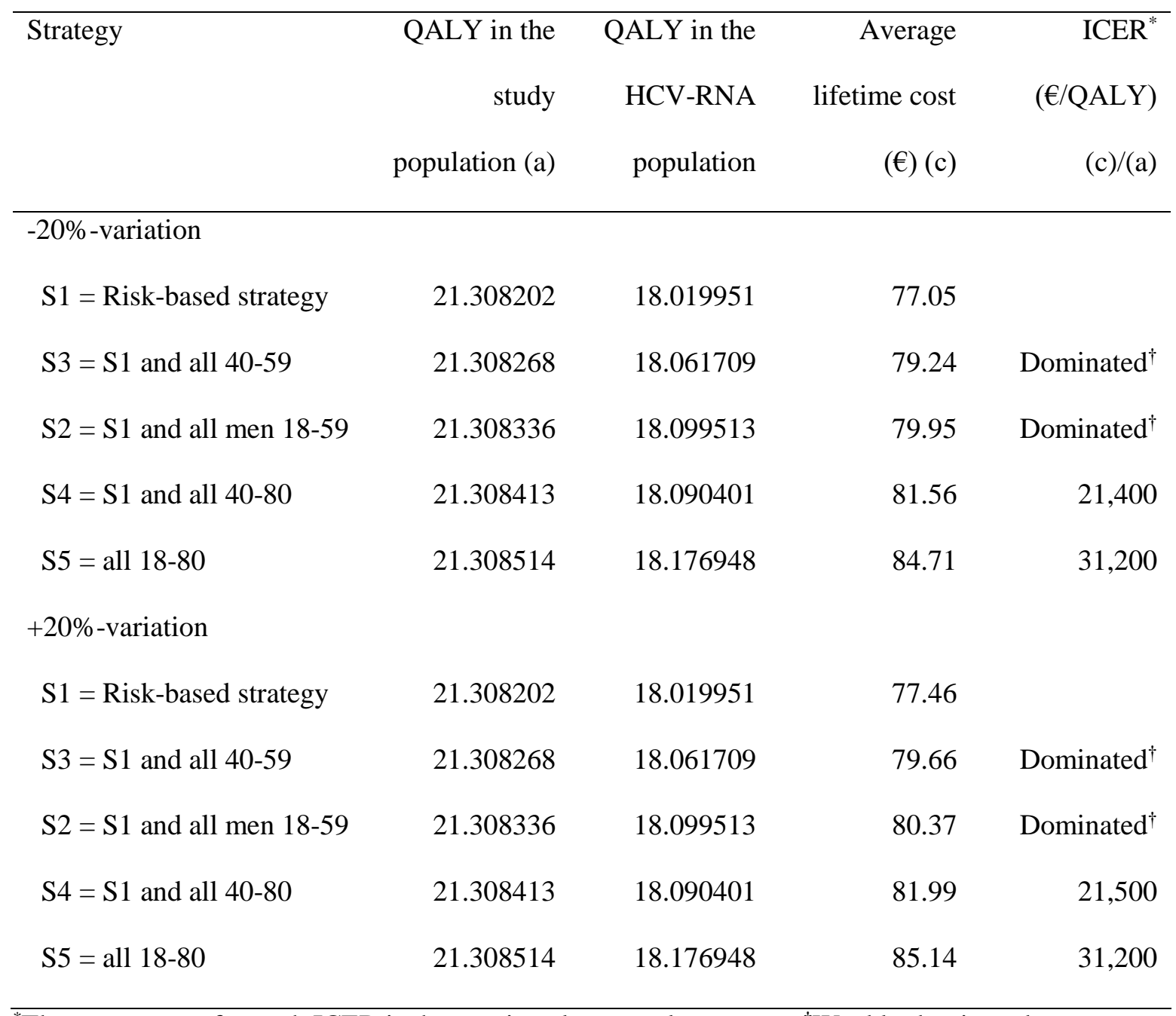

"The comparator for each ICER is the previous least costly strategy; ${ }^{\dagger}$ Weakly dominated strategy: higher ICER than that of a more effective alternative strategy. 
Supplementary Table 17 - Sensitivity analysis varying drugs cost by $\pm 20 \%$ : costeffectiveness analysis with treatment initiation regardless of fibrosis stage

\begin{tabular}{|c|c|c|c|c|}
\hline \multirow[t]{2}{*}{ Strategy } & $\begin{array}{r}\text { QALY in the } \\
\text { study }\end{array}$ & QALY in the & $\begin{array}{r}\text { Average } \\
\text { lifetime }\end{array}$ & $\begin{array}{r}\text { ICER* } \\
(€ / \mathrm{QALY})\end{array}$ \\
\hline & population (a) & population & $(€)(\mathrm{c})$ & (c)/(a) \\
\hline \multicolumn{5}{|l|}{$-20 \%$-variation } \\
\hline $\mathrm{S} 1=$ Risk-based strategy & 21.308202 & 18.019951 & 64.91 & \\
\hline $\mathrm{S} 3=\mathrm{S} 1$ and all $40-59$ & 21.308268 & 18.061709 & 67.05 & Dominated $^{\dagger}$ \\
\hline $\mathrm{S} 2=\mathrm{S} 1$ and all men $18-59$ & 21.308336 & 18.099513 & 67.66 & Dominated $^{\dagger}$ \\
\hline $\mathrm{S} 4=\mathrm{S} 1$ and all $40-80$ & 21.308413 & 18.090401 & 69.18 & 20,200 \\
\hline $\mathrm{S} 5=$ all $18-80$ & 21.308514 & 18.176948 & 72.18 & 29,700 \\
\hline \multicolumn{5}{|l|}{$+20 \%$-variation } \\
\hline $\mathrm{S} 1$ = Risk-based strategy & 21.308202 & 18.019951 & 89.60 & \\
\hline $\mathrm{S} 3=\mathrm{S} 1$ and all $40-59$ & 21.308268 & 18.061709 & 91.84 & Dominated $^{\dagger}$ \\
\hline $\mathrm{S} 2=\mathrm{S} 1$ and all men $18-59$ & 21.308336 & 18.099513 & 92.66 & Dominated $^{\dagger}$ \\
\hline $\mathrm{S} 4=\mathrm{S} 1$ and all $40-80$ & 21.308413 & 18.090401 & 94.37 & 22,600 \\
\hline $\mathrm{S} 5=$ all $18-80$ & 21.308514 & 18.176948 & 97.66 & 32,600 \\
\hline
\end{tabular}

"The comparator for each ICER is the previous least costly strategy; "Weakly dominated strategy: higher ICER than that of a more effective alternative strategy. 
Supplementary Table 18 - Sensitivity analysis varying the health-related utilities by $\pm 20 \%$ : cost-effectiveness analysis with treatment initiation regardless of fibrosis stage

\begin{tabular}{|c|c|c|c|c|}
\hline \multirow[t]{2}{*}{ Strategy } & $\begin{array}{r}\text { QALY in the } \\
\text { study }\end{array}$ & QALY in the & $\begin{array}{r}\text { Average } \\
\text { lifetime }\end{array}$ & $\begin{array}{r}\text { ICER* } \\
(€ / \mathrm{QALY})\end{array}$ \\
\hline & population (a) & population & $(€)(\mathrm{c})$ & (c)/(a) \\
\hline \multicolumn{5}{|l|}{$-20 \%$-variation } \\
\hline $\mathrm{S} 1=$ Risk-based strategy & 21.302473 & 14.810366 & 77.26 & \\
\hline $\mathrm{S} 3=\mathrm{S} 1$ and all 40-59 & 21.302531 & 14.847320 & 79.45 & Dominated $^{\dagger}$ \\
\hline $\mathrm{S} 2=\mathrm{S} 1$ and all men $18-59$ & 21.302598 & 14.884284 & 80.16 & 23,200 \\
\hline $\mathrm{S} 4=\mathrm{S} 1$ and all $40-80$ & 21.302660 & 14.872516 & 81.78 & 26,100 \\
\hline $\mathrm{S} 5=$ all $18-80$ & 21.302756 & 14.955148 & 84.92 & 32,700 \\
\hline \multicolumn{5}{|l|}{$+20 \%$-variation } \\
\hline S1 = Risk-based strategy & 21.313931 & 21.229536 & 77.26 & \\
\hline $\mathrm{S} 3=\mathrm{S} 1$ and all $40-59$ & 21.314005 & 21.276097 & 79.45 & Dominated $^{\dagger}$ \\
\hline $\mathrm{S} 2=\mathrm{S} 1$ and all men $18-59$ & 21.314074 & 21.314742 & 80.16 & Dominated $^{\dagger}$ \\
\hline $\mathrm{S} 4=\mathrm{S} 1$ and all $40-80$ & 21.314167 & 21.308285 & 81.78 & 19,200 \\
\hline $\mathrm{S} 5=$ all $18-80$ & 21.314272 & 21.398748 & 84.92 & 29,900 \\
\hline
\end{tabular}

"The comparator for each ICER is the previous least costly strategy; ${ }^{*}$ Weakly dominated strategy: higher ICER than that of a more effective alternative strategy. 
Supplementary Table 19 - Sensitivity analysis varying the probabilities of SVR by $\pm 5 \%$ : cost-effectiveness analysis with treatment initiation regardless of fibrosis stage

\begin{tabular}{|c|c|c|c|c|}
\hline \multirow[t]{2}{*}{ Strategy } & $\begin{array}{r}\text { QALY in the } \\
\text { study }\end{array}$ & QALY in the & $\begin{array}{r}\text { Average } \\
\text { lifetime }\end{array}$ & $\begin{array}{r}\text { ICER* } \\
(€ / \mathrm{QALY})\end{array}$ \\
\hline & population (a) & population & $(€)(\mathrm{c})$ & (c)/(a) \\
\hline \multicolumn{5}{|l|}{$-5 \%$-variation } \\
\hline $\mathrm{S} 1=$ Risk-based strategy & 21.307800 & 17.786905 & 79.16 & \\
\hline $\mathrm{S} 3=\mathrm{S} 1$ and all 40-59 & 21.307863 & 17.826463 & 81.37 & Dominated $^{\dagger}$ \\
\hline $\mathrm{S} 2=\mathrm{S} 1$ and all men $18-59$ & 21.307927 & 17.862278 & 82.08 & Dominated $^{\dagger}$ \\
\hline $\mathrm{S} 4=\mathrm{S} 1$ and all $40-80$ & 21.308000 & 17.853643 & 83.73 & 22,900 \\
\hline $\mathrm{S} 5=$ all $18-80$ & 21.308096 & 17.935635 & 86.89 & 32,900 \\
\hline \multicolumn{5}{|l|}{$+5 \%$-variation } \\
\hline S1 = Risk-based strategy & 21.308604 & 18.253021 & 75.35 & \\
\hline $\mathrm{S} 3=\mathrm{S} 1$ and all $40-59$ & 21.308673 & 18.296979 & 77.53 & Dominated $^{\dagger}$ \\
\hline $\mathrm{S} 2=\mathrm{S} 1$ and all men $18-59$ & 21.308745 & 18.336772 & 78.23 & Dominated $^{\dagger}$ \\
\hline $\mathrm{S} 4=\mathrm{S} 1$ and all $40-80$ & 21.308826 & 18.327184 & 79.82 & 20,100 \\
\hline $\mathrm{S} 5=$ all $18-80$ & 21.308932 & 18.418286 & 82.95 & 29,500 \\
\hline
\end{tabular}

"The comparator for each ICER is the previous least costly strategy; ${ }^{*}$ Weakly dominated strategy: higher ICER than that of a more effective alternative strategy. 
Supplementary Table 20 - Sensitivity analysis using alternative distribution of the study population [13]: cost-effectiveness analysis with treatment initiation regardless of fibrosis stage.

\begin{tabular}{lrrrr}
\hline Strategy & $\begin{array}{r}\text { QALY in the } \\
\text { study } \\
\text { population (a) }\end{array}$ & $\begin{array}{r}\text { QALY in the } \\
\text { HCV-RNA }\end{array}$ & $\begin{array}{r}\text { Average } \\
\text { lifetime cost }\end{array}$ & $\begin{array}{r}\text { ICER }^{*} \\
(€ / \text { QALY) }\end{array}$ \\
& 23.033705 & 19.614233 & 50.26 & \\
\hline S1 = Risk-based strategy & 23.033788 & 19.670585 & 52.65 & Dominated $^{\dagger}$ \\
S3 = S1 and all 40-59 & 23.033831 & 18.694380 & 53.26 & Dominated $^{\dagger}$ \\
S2 = S1 and all men 18-59 & 23.033853 & 19.683609 & 53.69 & 23,200 \\
S4 = S1 and all 40-80 & 23.033917 & 19.777793 & 57.18 & 54,500 \\
S5 = all 18-80 & & & &
\end{tabular}

"The comparator for each ICER is the previous least costly strategy; ${ }^{\dagger}$ Weakly dominated strategy: higher ICER than that of a more effective alternative strategy. 
Supplementary Table 21 - Sensitivity analysis of results considering costs related to severe anemia leading to transfusion for patients initiating ribavirin [25]: cost-effectiveness analysis with treatment initiation regardless of fibrosis stage

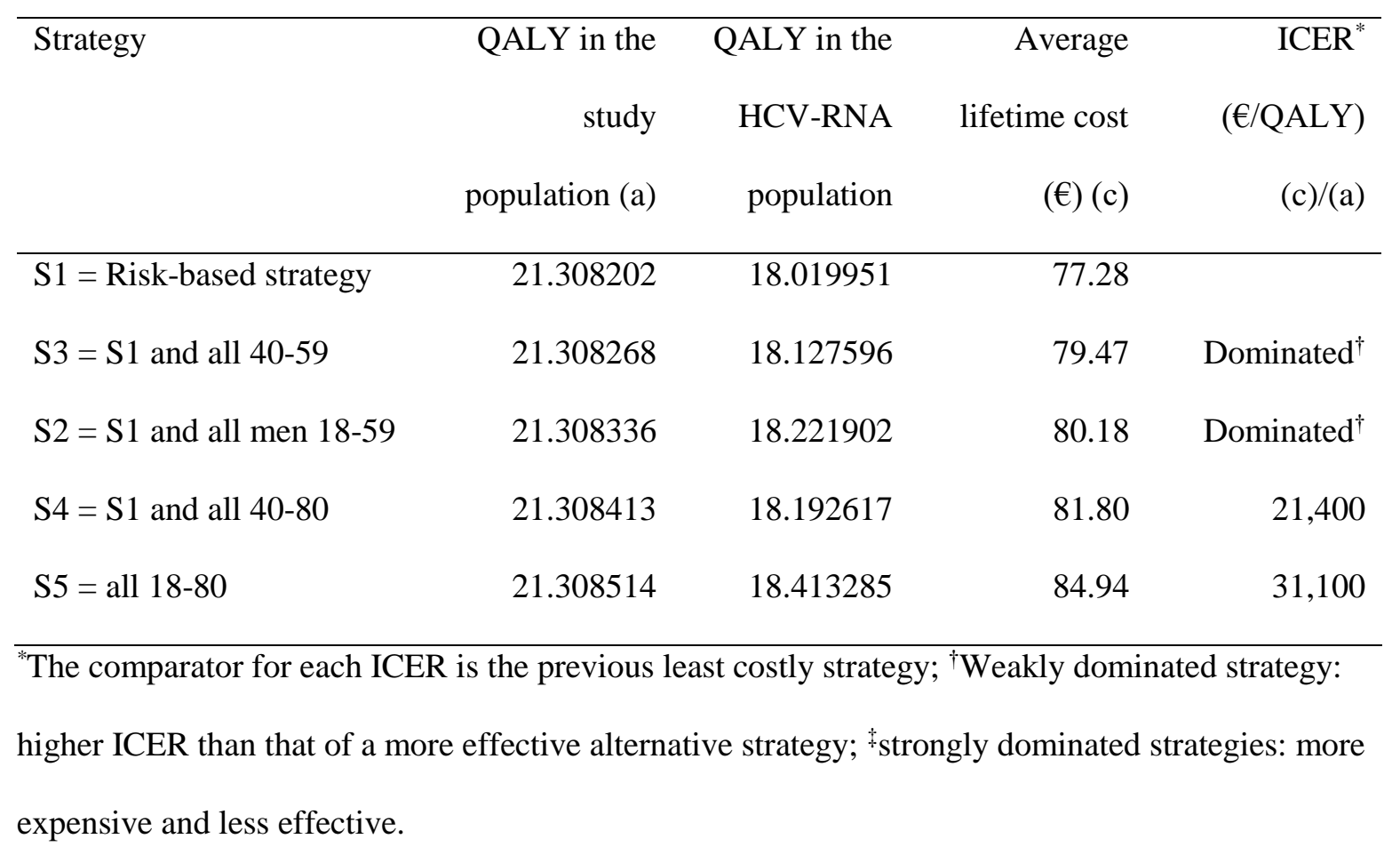


Supplementary Table 22 - Bivariate sensitivity analysis of increasing screening uptake from $50 \%$ to $100 \%$ and cost of screening (Hepatitis C antibody test, HCV-RNA test) from $0 \%$ to 20\%: average lifetime cost per person for the universal strategy and ICER for the universal screening strategy compared to the strategy targeting all individuals 40-80.

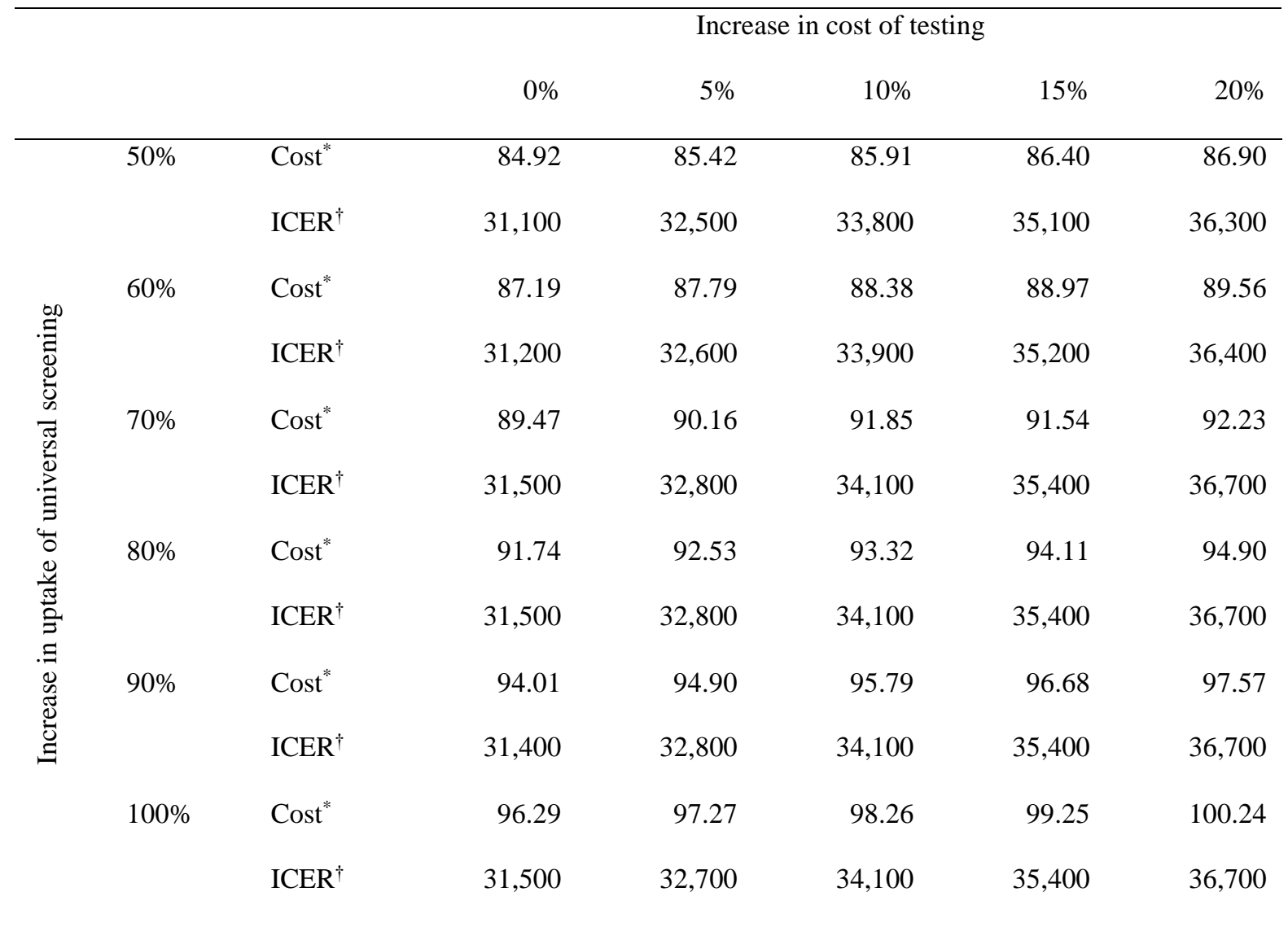

${ }^{\text {*Average lifetime cost per person in euros for universal screening; }{ }^{\dagger} \text { ICER in euros/QALY for universal }}$ screening compared to the strategy targeting all individuals $40-80$. 


\section{Supplementary References}

[1] The French METAVIR Cooperative Study Group. Intraobserver and interobserver variations in liver biopsy interpretation in patients with chronic hepatitis C. Hepatology 1994;20:15-20.

[2] Poynard T, Ratziu V, Charlotte F, Goodman Z, McHutchison J, Albrecht J. Rates and risk factors of liver fibrosis progression in patients with chronic hepatitis c. J Hepatol 2001;34:730-739.

[3] Serfaty L, Aumaitre H, Chazouilleres O, Bonnand AM, Rosmorduc O, Poupon RE, et al. Determinants of outcome of compensated hepatitis C virus-related cirrhosis. Hepatology 1998;27:1435-1440.

[4] Corrao G, Arico S. Independent and combined action of hepatitis C virus infection and alcohol consumption on the risk of symptomatic liver cirrhosis. Hepatology 1998;27:914-919. [5] Degos F, Christidis C, Ganne-Carrié N, Farmachidi J-P, Degott C, Guettier C, et al. Hepatitis $\mathrm{C}$ virus related cirrhosis: time to occurrence of hepatocellular carcinoma and death. Gut 2000;47:131-136.

[6] Davis GL, Alter MJ, El-Serag H, Poynard T, Jennings LW. Aging of hepatitis C virus (HCV)-infected persons in the United States: a multiple cohort model of HCV prevalence and disease progression. Gastroenterology 2010;138:513-521.

[7] Deuffic-Burban S, Mathurin P, Pol S, Larsen C, Roudot-Thoraval F, Desenclos JC, et al. Impact of hepatitis $\mathrm{C}$ triple therapy availability upon the number of patients to be treated and associated costs in France: a model-based analysis. Gut 2012;61:290-296.

[8] Mourad A, Deuffic-Burban S, Ganne-Carrié N, Renaut-Vantroys T, Rosa I, Bouvier AM, et al. HCC screening in patients with compensated HCV-related cirrhosis aware of their HCV-status improves survival: a modeling approach. Hepatology 2014;59:1471-1481. 
[9] D'Amico G, Garcia-Tsao G, Pagliaro L. Natural history and prognostic indicators of survival in cirrhosis: a systematic review of 118 studies. J Hepatol 2006;44:217-231.

[10] Agence de la Biomédecine. Rapport annuel 2011. Saint-Denis La Plaine; 2011.

[11] World Health Organiztion. Global Health Observatory Data Repository. Life Tables by country, France. 2013 [cited September 22, 2015]; Available from:

http://apps.who.int/gho/data/view.main.60580

[12] Meffre C, Le Strat Y, Delarocque-Astagneau E, Dubois F, Antona D, Lemasson JM, et al. Prevalence of hepatitis B and hepatitis C virus infections in France in 2004: social factors are important predictors after adjusting for known risk factors. J Med Virol 2010;82:546-555. [13] Brouard C, Le Strat Y, Larsen C, Jauffret-Roustide M, Lot F, Pillonel J. The undiagnosed chronically-infected HCV population in France. Implications for expanded testing recommendations in 2014. PLoS One 2015;10:e0126920.

[14] Assurance Maladie. Nomenclature générale des actes professionnels (NGAP) restant en vigueur depuis la décision UNCAM du 11 mars 2005. 2015 [cited July 22, 2015]; Available from: http://www.ameli.fr/fileadmin/user_upload/documents/NGAP.pdf [15] Assurance Maladie. Classification commune des actes médicaux. 2015 [cited July 22, 2015]; Available from: http://www.ameli.fr/fileadmin/user_upload/documents/CCAM_V40.pdf [16] Agence Technique de l'Information sur l'Hospitalisation. Manuel des GHM - Version définitive 11g. 2015 [cited July 23, 2015]; Available from: http://www.atih.sante.fr/manueldes-ghm-version-definitive-11g

[17] Cossais S, Schwarzinger M, Deuffic-Burban S, Pol S, Fontaine H, Larrey D, et al. EQ5D utility index in french patients with chronic hepatitis $\mathrm{C}$ (CHC) infection: severe comorbidities and perceived progression of $\mathrm{CHC}$ infection matter more than actual liver disease stage (P0745). J Hepatol 2015;62:S605. 
[18] Chevalier J, de Pouvourville G. Valuing EQ-5D using time trade-off in France. Eur J Health Econ 2013;14:57-66.

[19] Pol S, Chevalier J, Branchoux S, Perry R, Milligan G, Gaudin A-F. Health related quality of life and utility values in chronic hepatitis C patients: A cross-sectional study in France, the Uk and Germany (P0747). J Hepatol 2015;62:S606.

[20] Prise en charge thérapeutique et suivi de l'ensemble des personnes infectées par le virus de l'hépatite C. Rapport de recommandations 2016: Sous la direction du Pr Daniel Dhumeaux. Sous l'égide de l'ANRS et du CNS et avec le concours de l'AFEF.

[21] Mourad A, Deuffic-Burban S, Ganne-Carrie N, Renaut-Vantroys T, Rosa I, Bouvier AM, et al. Hepatocellular carcinoma screening in patients with compensated hepatitis $\mathrm{C}$ virus (HCV)-related cirrhosis aware of their HCV status improves survival: a modeling approach. Hepatology 2014;59:1471-1481.

[22] van der Meer AJ, Veldt BJ, Feld JJ, Wedemeyer H, Dufour JF, Lammert F, et al. Association between sustained virological response and all-cause mortality among patients with chronic hepatitis C and advanced hepatic fibrosis. JAMA 2012;308:2584-2593. [23] Agence Nationale d'Accréditation et d'Evaluation en Santé (ANAES). Hepatitis C screening - populations to be screened and screening procedures. Recommendations of the Experts Committee set up by the ANAES; 2001.

[24] Schwarzinger M, Deuffic-Burban S, Mallet V, Pol S, Pageaux GP, Canva-Delcambre V, et al. Lifetime costs attributable to chronic hepatitis C from the French healthcare perspective (Anrs N¹2188). J Hepatol 2013;58:S21-22.

[25] Agence Technique de l'Information sur l'Hospitalisation. Le programme de médicalisation des systèmes d'information en médecine, chirurgie, obstétrique et odontologie. [cited July 22, 2015]; Available from: http://www.atih.sante.fr/mco/presentation. 